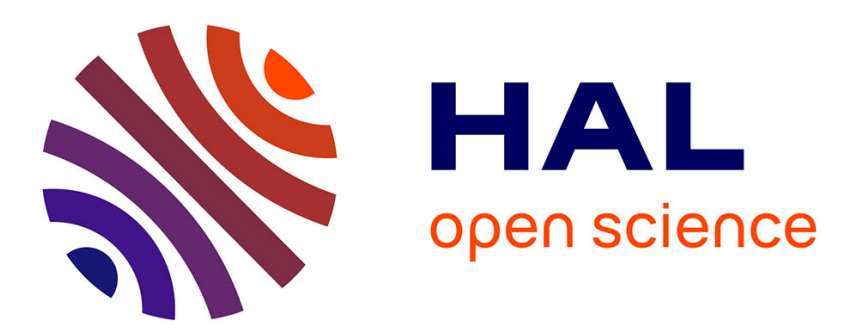

\title{
Autism: a world changing too fast for a mis-wired brain?
}

Bruno Gepner, François Féron

\section{To cite this version:}

Bruno Gepner, François Féron. Autism: a world changing too fast for a mis-wired brain?. Neuroscience and Biobehavioral Reviews, 2009, 33, pp.1227-1242. 10.1016/j.neubiorev.2009.06.006 . hal00483957

\section{HAL Id: hal-00483957 \\ https://hal.science/hal-00483957}

Submitted on 17 May 2010

HAL is a multi-disciplinary open access archive for the deposit and dissemination of scientific research documents, whether they are published or not. The documents may come from teaching and research institutions in France or abroad, or from public or private research centers.
L'archive ouverte pluridisciplinaire HAL, est destinée au dépôt et à la diffusion de documents scientifiques de niveau recherche, publiés ou non, émanant des établissements d'enseignement et de recherche français ou étrangers, des laboratoires publics ou privés. 
Référence de l'article:

Gepner, B. \& Féron, F. (2009). Autism: a world changing too fast for a mis-wired brain? Neuroscience and Biobehavioral Reviews, 33, 1227-1242.

\title{
Autism: a world changing too fast for a mis-wired brain?
}

\section{Bruno Gepner ${ }^{1}$ and François Féron ${ }^{2}$}

${ }^{1}$ Service de Psychiatrie de l'Enfant et de l'Adolescent, Centre Hospitalo-Universitaire, Liège, Belgique

Email: bruno.gepner@univ-provence.fr

2 NICN, CNRS UMR 6184, Institut Jean Roche, Faculté de Médecine, Université AixMarseille, Marseille, France

Email: francois.feron@univmed.fr

\begin{abstract}
Disorders in verbal and emotional communication and imitation, social reciprocity and higher-order cognition observed in individuals with Autism Spectrum Disorders (ASD) are presented here as phenotypic expressions of Temporo-Spatial Processing Disorders (TSPD). TSPDs include various degrees of disability in i) processing multi-sensory stimuli online, ii) associating them into meaningful and coherent patterns and iii) producing real-time sensorymotor adjustments and motor outputs. In line with this theory, we found that slowing down the speed of facial and vocal events enhanced imitative, verbal and cognitive abilities in some ASD children, particularly those with low functioning autism. We then argue that TSPDs may result from Multi-system Brain Disconnectivity-Dissynchrony (MBD), defined as an increase or decrease in functional connectivity and neuronal synchronization within/between multiple neuro-functional territories and pathways. Recent functional magnetic resonance imaging (fMRI) and electrophysiological studies supporting MBD are outlined. Finally, we review the suspected underlying neurobiological mechanisms of MBD as evidenced in neuroimaging, genetic, environmental and epigenetic studies. Overall, our TSPD/MBD approach to ASD may open new promising avenues for a better understanding of neuro-physio-psychopathology of ASD and clinical rehabilitation of people affected by these syndromes.
\end{abstract}

Key-words: autism spectrum disorders; temporo-spatial processing; motion; emotion; speech processing; imitation; cognition; rehabilitation; slowing down; connectivity; synchrony; neurotransmission.

Abbreviations: ASD (Autism Spectrum Disorders); TSPD (Temporo-Spatial Processing Disorders); MBD (Multisystem Brain Disconnectivity-Dissynchrony). 


\section{I- Introduction}

Autism and other related autism spectrum disorders (ASD) (Rapin, 2002) are known as behavioral syndromes including various degrees of verbal, nonverbal and social impairments as well as restricted or stereotyped interests and activities, with early onset (before 36 months) (WHO, 1992; APA, 2000), and long-lasting handicapping social and/or cognitive consequences. It is also currently accepted that these disorders altogether have a prevalence of about $0.6 \%$ (Fombonne, 2002) and constitute a major public health problem all over the world.

Although there is an international consensus for considering these syndromes as phenotypic expressions of impairments affecting the development of the Central Nervous System (CNS), numerous questions concerning the etio-pathology and physio-pathogeny of these affections are still unsolved. Their treatments are consequently unspecific and disappointing. Clinically, ASD remain enigmatic for numerous reasons. They represent a constellation (Gepner \& Tardif, 2006) of fairly heterogeneous disorders, that are rendered even more complex by the frequent association to mental delay, epilepsy, attention deficit with/without hyperactivity, language learning impairments - dysphasia, dyslexia - and obsessive compulsive disorders (Volkmar \& Pauls, 2003). Furthermore, anxiety and mood disorders often influence personality and behavior of individuals with ASD (Tardif \& Gepner, 2003; Lecavalier, 2006). Understanding the pathogenesis of ASD at molecular and cellular levels is an even more daunting task as it involves combinations of numerous genetic, epigenetic and environmental risk factors (Gepner \& Soulayrol, 1994; Persico \& Bourgeron, 2006) that affect different stages of neurodevelopmental and neurofunctional mechanisms.

In the present paper, we combine data from clinics, neuropsychology, neurophysiology, neuroimaging, genetics and epidemiology in a coherent approach to ASD. We first propose that Temporo-Spatial Processing Disorders (TSPD) of multi-sensory flows represent a common neuropsychological basis for the main behavioral, cognitive and motor disturbances observed in people with ASD. According to this hypothesis, ASD individuals would present various degrees of disability in processing dynamic multi-sensory stimuli online, associating them into meaningful and coherent patterns, and producing real-time sensory-motor adjustments and motor outputs. We also present results demonstrating that slowing down the speed of facial and vocal events enhance imitative, verbal and cognitive abilities of some ASD children. Then, we propose that TSPDs are based on Multi-system Brain Disconnectivity-Dissynchrony (MBD), i.e. disorders of functional connectivity and neural synchrony within/between multiple brain regions, and review the recent fMRI and electrophysiological data supporting MBD. Finally, we list the suspected neurobiological mechanisms underlying TSPDs and MBD.

\section{II- Temporo-spatial processing disorders (TSPD) of multi-sensory flows}

The TSPD hypothesis emerged from recurrent observations indicating that ASD patients exhibit various degrees of disability in i) perceiving and integrating environmental dynamic mutli-sensory stimuli online and ii) producing real-time sensory-motor coupling, postural adjustments and adequate verbal and nonverbal outputs.

\section{Neuropsychological findings}

It was first demonstrated that children with autism display a weak postural reactivity to visually perceived environmental motion (Gepner et al., 1995). Then, it was reported that i) children with low-functioning autism are posturally hypo-reactive to environmental movements, particularly when the speed of movement is high and ii) children with Asperger 
syndrome exhibit normal or even over-postural reactivity to the same type of stimuli (Gepner \& Mestre 2002a). This disordered (under- or over-) visuo-postural coupling in children with ASD may partly explain executive dysfunction in ASD patients (Hill, 2004 for a review) and sensory-motor and motor disturbances, such as poor motor coordination, poor or enhanced postural control, gross or fine motor clumsiness (Ornitz et al., 1974; Damasio and Maurer, 1978; Kohen-Raz et al., 1992; Leary \& Hill, 1996 and Green et al., 2009 for reviews). Interestingly, visuo-postural mis-coupling is a good example of sensory-motor coupling disorders described 40 years ago (Ornitz \& Ritvo, 1968; Ornitz, 1974).

In a second series of studies, it was demonstrated that ASD children have trouble perceiving the motion of small squares on a computer screen, especially at high speed and when the direction was less predictable (Gepner, 1997). Consistently, Bertone et al. (2003) showed that high-functioning autistic subjects exhibit a deficit in the perception of second order radial, translational and rotational direction of movement (see also Dakin \& Frith, 2005, for a review).

Additional evidence supporting TSPD hypothesis stem from observed impairments in children and adolescents with ASD who were tested for their ability to extract online relevant information among noisy stimuli, through 3 types of tasks and measurements: a) oculo-motor reactivity to global movement of a coherent pattern of lighting points (a random dot kinematogram) through opto-kinetic nystagmus, b) speech flow perception and segmentation through categorization of simple and complex phonemes, and c) proprioception and motor anticipation in a bimanual load lifting task, through electromyographic and kinematic index (Gepner \& Massion (dir. by), 2002).

First, the group of ASD subjects showed weak oculo-motor reactivity in response to global motion, i.e. higher motion coherence thresholds, when compared to control children (Mestre et al., 2002), as also observed by others (Spencer et al., 2000; Milne et al., 2002 ; Pellicano et al., 2005; Milne et al., 2005 for a review). Noticeably, this weaker oculo-motor reactivity was observed in reaction to high motion velocities (Mestre et al., 2002). This deficit, which supposes a defect in rapid temporal analysis of visual-motion stimuli embedded in noise, is a strong argument for a degraded temporo-spatial integration in the visual modality. Interestingly, this difficulty to integrate single points into a global coherent motion is also an argument for weak central coherence (Mestre et al., 2002; Pellicano et al., 2005). Impaired oculomotor reactivity to fast visual-motion, along with above-mentioned results demonstrating postural hypo-reactivity to fast environmental movements in children with autism and results suggesting impairments in rapid human movements processing (see below), led us to propose the rapid visual-motion integration deficit hypothesis of autism (Gepner \& Mestre, 2002b).

Second, the same group of ASD subjects exhibited a deficit in speech phoneme categorization. Compared to control children who categorized an ambiguous phoneme such as MNA (made of an algorithmic superimposition of MA and NA) in a MA or a NA random response, autistic children over-categorized MNA in a NA response. This deviant overcategorization specifically appeared in autistic subjects when speech phonemes were displayed at normal speed, whereas their phoneme categorization was normalized when phonemes were slowed down by a factor of 2 . Phoneme categorization deficit may partly be due to a difficulty in rapid speech flow processing and thus to a temporal integration deficit in the auditory modality (Tardif et al., 2002). As a consequence, the deficit may account for the receptive and expressive language and verbal communication impairments observed in individuals with ASD. Given the parallel between language disorders in ASD and developmental language disorders (Rapin \& Dunn, 2003), it is not surprising that the same deficit was found in children with language learning impairments (Tallal, 1976), and was ameliorated by slowing down the speed of speech flow (Tallal et al., 1996; Gaab et al., 2007; 
Tallal and Gaab, 2006 for a review). In line with these results, Oram Cardy et al. (2005), measuring evoked neural activity (M50, M100) to two $40 \mathrm{~ms}$ tones passively presented in rapid succession via magnetoencephalography, found that $80 \%$ of individuals with intact language (Asperger syndrome, typical development, normal adults) responded to the second tone, which required rapid temporal processing demands, while $65 \%$ of patients with impaired language (autism, specific language impairment) failed to do so, although they had reacted to the first tone. The authors concluded that deficient rapid temporal processing may contribute to impaired language development by interfering with the processing of brief acoustic transitions, crucial for speech perception.

Third, it was found that a subgroup of the same autistic subjects displayed a deficit in motor anticipation in a bimanual load-lifting task (Schmitz et al., 2002; see also Schmitz et al., 2003). The task requires the rapid processing of proprioceptive inputs, the correct use of an internal representation of the weight to be load-lifted and the precise adjustment of the timing of muscular events. Compared to control children using a feed-forward mode of control to stabilize their forearm while lifting an object placed on it, autistic children mostly use a feedback mode of control, which results in slowing down their movement. In other words, autistic children are reacting instead of predicting. This deficit of accurate timing of anticipatory control partly results from an impaired processing of proprioceptive inputs, at least during the learning phase of the task, and thus from a temporo-spatial integration deficit in the proprioceptive modality. This impairment, along with visual-proprioceptive processing deficit (i.e. deficit of visuo-postural and visuo-oculomotor reactivity), may contribute to executive dysfunction in ASD people (Hughes et al., 1994; Hill, 2004 for a review) and particularly to slowed sensory-motor processing speed.

As a result, many ASD individuals display deficits in temporo-spatial integration of sensory inflow which is necessary to i) detect and integrate visual motion, ii) code and parse language, and iii) anticipate and program postural adjustments. To briefly summarize, the environmental world may be changing too fast in one or several sensory modalities for at least some ASD children and adults.

\section{Slowing down sensory stimuli as a tool for rehabilitation?}

If the world is changing too fast for some ASD individuals, would it be beneficial to slow it down?

It was first found that ASD subjects, who usually perform poorly in facial recognition tasks involving the processing of facial dynamics (e.g. Hobson et al., 1988; De Gelder et al., 1991; Gepner et al., 1996), perform equally as well as typically developing children of the same developmental age in emotional and facial speech recognition tasks when the stimuli are slowly displayed on video (Gepner et al., 2001). In a complementary study, Tardif et al. (2007) strenghtened these results by demonstrating that some children with autism, particularly those having the more severe autistic syndrome, recognize significantly more emotional and non-emotional facial expressions, and exhibit more facial-vocal induced imitation when facial expressions and their corresponding vocal sounds are slowed down in an ecological or artificial way.

Next, in order to further test how slowing down facial and vocal cues would impact imitative and cognitive performance in autistic children, our group devised software that slows down simultaneously visual and auditory cues. We observed that slowing down the presentation of facial and body gestures enhanced voluntary imitation of ASD children (especially the more affected ones), whereas such improvement was not seen in healthy children or in mentally retarded ones (Lainé et al., 2008a). Similarly, it was found that slowing down the visual and auditory presentation of single or double sentences enhance verbal comprehension, 
particularly in children with low-functioning autism (Lainé et al., 2008b; Lainé et al., in press).

Overall, these findings may be of potential high interest for rehabilitating verbal and emotional communication disorders in at least some individuals with ASD.

\section{What does TSPD hypothesis predict for behavior and cognition?}

According to our hypothesis, TSPD-exhibiting ASD individuals would tend to avoid rapid visual, auditory or proprioceptive flows, considered as aversive stimuli. Moreover, they would inadequately perceive and respond to rapid physical and human movements, especially facial movements such as eye movements (which are the most rapid ones in humans), lip movements and emotional facial gestures, but also body movements. As a consequence, TSPDs would induce impairments in i) attention to faces (e.g. decreased visual fixations to the eye region, see Hutt et al., 1964; Klin et al., 2002; Dalton et al., 2005; Speer et al., 2007), ii) facial imitation (Loveland et al., 1994; Vivanti et al., 2008), iii) recognition of facial stimuli involving motion or emotion (e.g. Hobson et al., 1988; De Gelder et al., 1991; Davies et al., 1994; Gepner et al., 1996; Critchley et al., 2000; Dawson et al., 2005 for a review; Hadjikhani et al., 2007; Pelphrey et al., 2007), and iv) action imitation (e.g. DeMyer et al., 1972; Rogers \& Pennington, 1991; Rogers et al., 2003; Williams et al., 2004 for a review). In addition, impairments in rapid auditory processing would induce deficits in phoneme categorization, verbal imitation, verbal comprehension and finally in verbal and language abilities (Rapin \& Dunn, 2003 and Tager-Flusberg \& Caronna, 2007 for reviews). These numerous disabilities are likely to disrupt verbal and emotional communication and therefore to be detrimental for social interaction between ASD subjects and their human environment (Gepner \& Tardif, 2006).

TSPD hypothesis postulates that the environmental world is changing too fast to be processed on time, and therefore also predicts that some ASD individuals would exhibit a slowed processing speed (see e.g. Welsh et al., 2005), in motor (see above Schmitz et al., 2002, 2003), perceptual and cognitive acts. For example, subjects with ASD exhibit slowed attentional processes such as shifting or orientating spatial attention (Wainwright-Sharp \& Bryson, 1993; Townsend et al., 1996). Nishitani et al. (2004) observed that adults with Asperger syndrome display a delayed cortical activation from occipital cortex to superior temporal sulcus, inferior parietal lobe and inferior frontal lobe, when imitating still pictures of lip forms. McPartland et al. (2004) found electrophysiological evidence for slowed neural speed of face processing in autism. Wong et al. (2008) found that event related potentials (ERP), relating to face detection (visual cortex) and configural processing of faces (fusiform gyrus), as well as mental state decoding (medial prefrontal lobe), were significantly weaker and/or slower in autism, when compared to controls, during both explicit and implicit emotion-processing tasks. Finally, Schmitz et al. (2007) demonstrated that ASD individuals responded significantly more slowly than their controls during a cognitive assessment task, and that this reduced processing speed was correlated to decreased frontal lobe parenchymal volume.

Since the dynamic environmental world seems difficult to handle for ASD individuals, TSPD hypothesis additionally predicts an overfocused attention to static visual stimuli (Burack et al., 1997 and Mottron, 2004, for reviews) and auditory singularities (e.g. Mottron et al., 2000). Consequently, a weak central coherence (Frith, 1989; Happé, 1999; Happé \& Frith, 2006), enhanced abilities in spatial memory and graphism, and increased pitch sensitivity (Bonnel et al., 2003; Mottron, 2004 for a review) may be observed.

Similarly, TSPD hypothesis predicts that some ASD individuals may develop compensatory mechanisms, via sensory-motor over-coupling (e.g. Gepner \& Mestre, 2002a), sometimes 
leading to high levels of performance and over-abilities in some fields. Others may also search for, habituate themselves and learn to handle and cope with, rapid dynamic stimuli and become more and more capable to process them (Gepner, 2004, 2008). Finally, a fraction of ASD individuals would search to slow down the speed of sensory inflow (see Williams' statement below).

\section{Clinical arguments for TSPD}

How do clinical observations support TSPDs? Several reports from ASD adults are in accordance with the rapid visual-motion integration deficit hypothesis of autism (Gepner \& Mestre, 2002b) and support our TSPD approach.

The link between TSPDs and gaze aversion was substantiated by Temple Grandin who declared (1995) that "some of the problems autistics have with making eye contact may be nothing more than intolerance for the movement of the other person's eyes. One autistic person reported that looking at people's eyes was difficult because the eyes did not stay still".

On the connection between time, space, speed and movement (i.e., TSPD), on the one hand, and weak central coherence, on the other hand, Van Dalen (1994), an adult with mild autism, stated: "For me, time seems to flow out rapidly, or in other terms, a non-autistic person sees me as living slowly. During a certain period of time a non-autistic person can digest more percepts than me because I am constrained to digest each object piece by piece...Time phenomenon is relative to space, and strongly related to the number of distinct entities to be processed. I like to compare eyes of autistic persons to those faceted eyes of insects: there are numerous different subtile details, but they are not integrated together... ».

Concerning the behavioral consequences of an excessively rapid environment and the potential usefulness of slowing down the sensory environment for ASD patients, Donna Williams (1992) wrote that "the constant change of most things never seemed to give me any chance to prepare myself for them. Because of this I found pleasure and comfort in doing the same things over and over again. I always loved the saying, 'Stop the world, I want to get off'. The stress of trying to catch up and keep up often became often too much and I found myself trying to slow everything down and take some time out... One of the ways of making things seem to slow down was to blink or to turn the lights on and off really fast. If you blinked really fast, people behaved like in old frame-by-frame movies, like the effect of strobe lights without the control being taken out of your hands" (p. 39-40).

Another statement by Temple Grandin (1995) accounts for the various visual behavior impairments along the 'autistic continuum' (i.e. autism spectrum): "Minor sensory processing deficits heightened my attraction to certain stimulation (e.g. airport's doors), whereas a greater sensory processing defect might cause another child to fear and avoid the same stimulus".

About the auditory modality, Daniel Tammet (2006), an autistic savant, mentioned that "she spoke very fast and I found it difficult to follow her...the rapid succession of questions was intrusive... and it took me some time to answer her".

Long before these self reports by ASD adults, Kanner (1943) in the first description of autistic children in the literature, observed several peculiarities of visual behavior such as i) gaze or face avoidance, ii) visual avoidance or visual attraction for moving, spinning and rolling objects, iii) visual attraction for details of objects, static patterns and puzzles, iv) sensory-motor disorders, such as motor clumsiness, awkwardness, as well as hand, arm or body stereotypes. One should notice that all these symptoms directly or indirectly question the way ASD children attend to, perceive, integrate and interact with, their dynamic versus static environment (Gepner, 2001). 
Confirming the importance of such a question, studies using family home movies in the last two decades identified early specific visual, auditory and sensory-motor mis-behaviors in the first (Zwaigenbaum et al., 2005) or second year (Werner \& Dawson, 2005) of life in ASD children.

In the domain of visual behavior, in the first six months of life, autistic babies may exhibit early atypicalities of gaze contact and ocular pursuit of moving objects or individuals (Adrien et al., 1993; Sauvage, 1988) and prolonged latency to disengage visual attention (Zwaigenbaum et al., 2005). Between 6 and 12 months, while exhibiting atypical interests for their hands and focusing on particular static objects in the environment (Adrien et al., 1993; Zwaigenbaum et al., 2005), they may also display a lack of interest for moving games and objects and self-stimulating sensory and sensory-motor behaviors, like finger- and handflapping in front of their eyes (Adrien et al., 1993; Osterling \& Dawson, 1994). Overall, vision in ASD infants appears to be dissociated between a poor or avoided dynamic vision, frequently followed by self-stimulation of dynamic vision, and an enhanced static vision, with visual attraction and overfocused attention to details and singularities, at the expense of global or contextual information (Gepner, 2001, 2008). While autistic babies generally display a developmental delay (the 'negative signs of autism'), they also show atypical selfstimulating visual, auditory and sensory-motor behaviors (the 'productive signs of autism'), some of which probably have an adaptive and/or compensatory value. These compensatory strategies may mask the primary dysfunctions (Belmonte et al., 2004b). For example, visual attraction for rapidly moving stimuli possibly veils a primary dysfunction in processing such stimuli.

In regard to the domain of auditory behavior, babies who will later be diagnosed as autistic often fail to orient to their name and present a delayed development of expressive and receptive language (Zwaigenbaum et al., 2005; Werner \& Dawson, 2005), possibly as a consequence of a failure to catch the rapid dynamic aspect of verbal flow. Concerning motor development, babies who will later exhibit typical autism (Teitelbaum et al., 1998) or Asperger syndrome (Teitelbaum et al., 2004) show disturbances in some or all of the milestones of development, including lying, righting, sitting, crawling and walking. In addition, Adrien et al. (1993) and Sauvage (1988) observed that they frequently exhibit deficits of postural adjustment, a lack or a delay in anticipating attitudes as well as in oculomanual coordination, all of these symptoms being possibly due to a distorted proprioceptive and visuo-postural integration, and stereotyped behaviors like swinging, rocking and swaying, possibly aimed at compensating it.

The time course of autistic symptoms during infanthood may then appear as succession and intrication of maldevelopmental cascades, in which early temporo-spatial processing disorders of visual, auditory and proprioceptive stimuli impact secondarily on i) sensorymotor development, ii) verbal and emotional communication and social interactions between a baby and his physical and human environment (Gepner, 2004; Belmonte et al., 2004b; Gepner \& Tardif, 2006; Gepner, 2008). One of these maldevelopmental consequences has been named E-Motion Mis-sight, i.e. various degrees of disability in perceiving and integrating motional and emotional stimuli on time (Gepner, 2001; Gepner et al., 2005; Gepner, 2008). E-Motion Mis-sight has been proposed to be an early precursor of mindblindness (Baron-Cohen, 1995; Frith, 2001) and empathizing deficit (Baron-Cohen, 2002).

In summary, TSPDs of multi-sensory stimuli may account for numerous clinical and neuropsychological findings in ASD that are synthesized and articulated below, and schematized on Figure 1: 
i) Impairments in perceiving and integrating physical movements, that may account, alone or in conjunction with proprioceptive flow processing deficits, for executive dysfunction, as well as for slowed perceptual and sensory-motor processing speed.

ii) Impairments in perceiving and integrating biological motion such as:

a. eye movements, that may result in eye direction detection deficit, eye contact disorders, joint attention deficit and mindblindness,

b. lip movements, that may result, alone and in conjunction with speech flow processing deficit, in visuo-auditory association disorders, and in language impairments,

c. emotional facial and body movements, that may result in E-Motion Mis-sight, empathizing deficit and mindblindness, as well as in facial and body processing deficits and peculiarities.

These impairments may also consequently account for slowed perceptual and cognitive processing speed and imitative impairments.

iii) Dynamic auditory processing deficits that may result in phoneme categorization impairment, and, in conjunction with lip movements processing deficits, may account for visuo-auditory association deficits, verbal imitation deficits and language impairments.

iv) Over-focused attention on static visual stimuli that may explain enhanced local perception and weak central coherence, enhanced spatial memory and sometimes enhanced graphic abilities; overfocused attention on auditory singularities that may trigger enhanced pitch sensitivity.

v) Enhanced facial expression recognition, increased facial and body imitation and improved verbal comprehension when visual and/or auditory stimuli are slowed down.

\section{Suspected neurobiological correlates of TSPD}

When in search for the neurobiological bases of TSPDs, we hypothesized they may be based on deficits in temporal encoding of multi-sensory inputs, temporal coupling of sensory-motor events, and temporal production of motor outputs (Gepner \& Massion (dir by), 2002). The cerebellum (i.e. the clock of the brain as stated by Massion, 1993) is known to play a crucial role in all these stages. First, visual inputs, especially dynamic ones, travel through mossy fibres via the pontine nuclei before reaching the cerebellum (Glickstein \& Stein, 1991). Second, the cerebellum plays a major role in speed and temporal coding and therefore in integrating multi-sensory dynamic inputs (e.g. Johnson \& Ebner, 2000). Third, the cerebellum exerts a real-time fine tuning of movement (e.g. Ito, 1984). Fourth, the cerebellum contributes with the basal ganglia to motor control as well as to learning (Doya, 2000), via projections on motor and premotor cortices as well as on prefrontal, temporal and parietal cortices (Middleton \& Strick, 2000). Yet, some of the most consistent neuroanatomic anomalies affecting people with ASD are likely to affect the cerebellum (e.g. Courchesne et al., 1988, 1994; see also below). Visuo-cerebellar pathways, among other sensory-cerebellar pathways, are therefore highly suspected to be involved in the neurophysio-pathology of ASD (Takarae et al., 2004) and could explain the unusual visuo-motor reactivity and, possibly, the bizarre cognitive style and higher-order cognitive peculiarities observed in this population (Gepner \& Mestre, 2002b).

Convergent with our proposal, Welsh et al. (2005) proposed to link neuroanatomic abnormalities of the cerebellum with cognitive impairments in ASD. The authors surmised that disturbances in the inferior olive structure found in autism (see e.g. Kemper \& Bauman, 1993; Bailey et al., 1998), and consequently in olivo-cerebellar pathways, would disrupt the ability of inferior olive neurons to become electrically synchronized and generate coherent rhythmic output. These anomalies of synchronization would i) impair the ability of individuals with ASD to process rapid information (e.g. their ability to use rapid sequences of 
cues for the development of normal language skills), and ii) result in slowing their perceptual and cognitive processing speed. Following Welsh et al. (2005), rapid sensory information (rapid sensory flows) would arrive too quickly to be processed on time by the autistic brain. Appropriately, a neuromimetic model (i.e. a mathematic model simulating brain functioning) of brain connectivity found that the speed of synchronization depends on the dynamical and network parameters, and is most probably limited by the network connectivity (Timme et al., 2004).

\section{III- Multisystem Brain Disconnectivity-Dissynchrony (MBD)}

In an attempt to further understand the neurophysiological basis of TSPDs in ASD, we propose the concept of Multisystem Brain Disconnectivity-Dissynchrony (MBD), defined as an increase or decrease of functional connectivity and neural synchrony within/between multiple cortical and subcortical regions of the brain (Figure 2).

Before reviewing the recent functional brain imaging and electrophysiological studies supporting our MBD approach to ASD, it should be emphasized that numerous data emerging from i) animal and human physiology (Varela et al., 2001, for a review), ii) human psychophysiopathology (Babiloni et al., 2004 for epilepsy; Symond et al., 2005 for schizophrenia; Just et al., 2004 for autism) and iii) neuromimetic models (e.g. Borgers \& Kopell, 2003; Breakspear, 2004), evidenced functional interdependence and equivalence between neural synchronization (at the level of neuron assemblies), brain rythmicity and functional connectivity. Neural synchrony can therefore be considered as a mechanism of temporal connectivity.

\section{Functional Magnetic Resonance Imaging (fMRI) studies}

Functional connectivity is the mechanism allowing the achievement of a cognitive task or perceptual process by coordinating and spatio-temporally correlating activities between different neural assemblies (Fingelkurts et al., 2005). Based on several arguments, some authors have suspected that the functional connectivity between brain areas could be abnormal in subjects with ASD (Horwitz et al., 1988; Brock et al., 2002; Castelli et al., 2002; Belmonte et al., 2004a). Studies using functional magnetic resonance imaging (fMRI) during the past 5 years have confirmed that functional brain connectivity could either be decreased (see Wickelgren, 2005, Geshwind \& Levitt, 2007 and Minshew \& Williams, 2007 for reviews), or sometimes increased (Rippon et al., 2007 for a review) in subjects with ASD, during either resting state and simple or complex cognitive tasks.

Under resting state, Cherkassky et al. (2006) observed that, although the anterior and posterior midline regions were similar in volume and in organization in ASD subjects and control individuals, a functional under-connectivity between these regions was observed in ASD individuals.

During sentence comprehension tasks, Just et al. (2004) found a diminished functional connectivity between Wernicke's area and Broca's area in autistic subjects. In another sentence comprehension task with imagery content, Kana et al. (2006) showed that the language and spatial centres in autistic patients were not as well connected as in controls.

In an inhibition task, Kana et al. (2007) observed that subjects with autism exhibited a decreased connectivity between anterior and middle cingulate gyri, and insula, on the one hand, and the right middle, inferior frontal and right inferior parietal regions, on the other hand. In an executive function task, Just et al. (2007) demonstrated an under-connectivity between frontal and parietal regions in autistic subjects. 
In a visuo-motor task, Villalobos et al. (2005) described a decreased functional connectivity between V1 and bilateral inferior frontal cortex. However, during another visuo-motor coordination task, Turner et al. (2006) showed that, although there was a decreased connectivity between associative, orbitofrontal oculomotor and motor circuits in subjects with autism, the same individuals exhibited a diffuse increased connectivity, mostly in pericentral regions and visual cortex. Similarly, in another visuo-motor coordination task, Mizuno et al. (2006) demonstrated a more extensive connectivity between thalamus and cortex (especially left insula, right postcentral and middle frontal regions) in autistic subjects. For these authors, this hyper-functional subcortico-cortical connectivity could potentially compensate a reduced cortico-cortical connectivity.

During facial identity processing, Kleinhans et al. (2008) found that greater social impairments were correlated to reduced connectivity between fusiform face area (FFA) and amygdala, and increased connectivity between FFA and right inferior frontal cortex in subjects with ASD.

Furthermore, Wicker et al. (2008) demonstrated that, whereas subjects with ASD perform equally as well as healthy controls when viewing emotional expressions, they present abnormal patterns of effective connectivity (which is defined as the influence one system exerts over another in respect to a given experimental context, Büchel and Friston, 2000). What was found in autistic subjects compared to controls was mainly under-connectivity (e.g. between V1/V2 and fusiform gyrus, between amygdala and dorso-medial prefrontal cortex, and between ventro-lateral prefrontal cortex and STS), but over-connectivity was also found between right dorso-lateral prefrontal cortex (dLPFC) and fusiform gyrus. As suggested by the authors, an abnormally strong influence of right dLPFC on fusiform gyrus could represent the neural instantiation of a compensatory cognitive mechanism that would explain the similar levels of performance in the explicit emotional task in both groups.

Finally, Kennedy and Courchesne (2008) recently showed that there was an altered functional organization of the network involved in social and emotional processing in autistic subjects but no group difference in the functional organization of the network involved in sustained attention and goal-directed cognition. This finding is in accordance with the Systemizing-Empathizing and Extreme male brain theories of autism (Baron-Cohen, 2002; Baron-Cohen et al., 2005).

In order to take into account not only under- but also over-connectivity between multiple brain areas in ASD, we proposed to name these processes multisystem functional disconnectivity (Gepner et al., 2005; Gepner \& Tardif, 2006; Tardif et al., 2007; Gepner, 2008).

\section{EEG and MEG studies}

Functional MRI studies are useful to investigate the interaction between brain areas in ASD. However, these investigations provide only indirect evidence for dysfunctional neural synchrony in ASD, as interactions between and within brain areas occur with a precision in the millisecond range, a time resolution that fMRI cannot provide (Singer, 2007). As also stated by Singer (2007), most of the brain's cognitive functions (such as perceptual organization, memory and attention) and executive functions are based on the coordinated interactions of large numbers of neurons that are distributed within and across different specialized brain areas. Transient synchronization of neuronal discharges in the beta (13-30 $\mathrm{Hz}$ ) and gamma $(30-80 \mathrm{~Hz})$ frequency ranges has been proposed as possible mechanism to dynamically bind widely distributed sets of neurons into functionally coherent ensembles that represent the neural correlates of a cognitive content or an executive program (Singer, 1999). 
A new generation of experiments on neural synchrony using EEG coherence during both resting conditions and simple or complex cognitive tasks has emerged. Findings obtained through these experiments parallel and complete results obtained in fMRI sudies.

Assessing functional connectivity with electroencephalographic coherence among adults with ASD and control adults in an eyes-closed resting state, Murias et al. (2007) found patterns of over- and under-connectivity that were apparent at distinct spatial and temporal scales.

In another eyes-closed resting condition study, Coben et al. (2008) also found dysfunctional integration of frontal and posterior brain regions in autistic subjects along with a pattern of neural under-connectivity.

In the domain of complex visual processing, Brown et al. (2005) showed an overall increased gamma-activity in individuals with autism in comparison to healthy individuals whilst identifying the presence or absence of an illusory Kanizsa shape. This abnormal gamma activity was interpreted as a decreased "signal to noise" processing due to decreased inhibitory processing in ASD.

In regard to auditory processing, Wilson et al. (2007) used magnetoencephalography to examine the integrity of local circuitry by focusing on gamma band activity in auditory cortices of children and adolescents with autism and control subjects, while listening to 500 ms duration monaural click trains with a $25 \mathrm{~ms}$ inter-click interval. The authors demonstrated that the production and/or maintenance of left hemispheric gamma oscillations appeared abnormal in participants with autism. These findings evidence that aberrations in local circuitry could underlie putative deficiencies in long-range neural communication. Specifically, the authors suggest that deficits in neural synchrony may not exclusively involve long-range synchronization between cortical regions, but also local synchronization within cortical areas. According to Singer (2007), these findings add crucial evidence that precise timing of neural activity is disturbed in ASD, suggesting the possibility that this impairment may underlie the deficits in cognition and behavior associated with the disorder.

Studying sustained visual attention, Orekhova et al. (2007) investigated whether beta and gamma range EEG abnormalities are characteristic for young boys with autism. EEG was recorded during sustained visual attention in two independent samples of autistic boys aged 3 to 8 years, and in age matched typically developing boys. In both samples, boys with autism demonstrated a pathological increase of gamma $(24.4-44.0 \mathrm{~Hz})$ activity. According to the authors, given the important role of high frequency EEG rhythms for perceptual and cognitive processes, early abnormalities in the neuronal mechanisms generating high frequency EEG rhythms may contribute to the development of the disorder.

Altogether, findings from fMRI and EEG coherence studies evidenced modifications in functional connectivity and neural synchronization in the brain of ASD patients, during resting state and cognitive tasks. What seems to emerge from the latter studies is that when they have to process dynamic visual (such as facial movements) and auditory stimuli (such as click trains and verbal speech), subjects with ASD generally exhibit functional underconnectivity or neuronal hypo-synchronization. Conversely, when sustaining attention or processing static visual stimuli, subjects with ASD generally exhibit over-connectivity or hyper-synchronization. Also supporting these findings, Pelphrey et al. (2007) found a lack of modulation of social brain regions including the amygdala, posterior superior temporal sulcus and fusiform gyrus by dynamic versus static emotional expressions.

The co-occurrence of a disconnected and dissynchronized brain led us to propose the unifying concept of Multisystem Brain Disconnectivity-Dissynchrony (MBD), which may be a key signature of the developmental and functional brain anomalies observed in ASD patients.

It should finally be added that numerous areas and pathways involved in motion, emotion, facial and auditory processing in daily life, are functioning or highly suspected to function inadequately in ASD subjects. Among the most studied, we can cite the visual magnocellular 
system (Gepner \& Mestre, 2002b; Milne et al., 2002; Deruelle et al., 2004), the dorsal stream (e.g. Pellicano et al., 2005; Spencer et al., 2000; Villalobos et al., 2005), the cerebellum (e.g. Courchesne et al., 1988, 1994; Allen and Courchesne, 2003), and especially the "social brain", i.e. the amygdala (e.g. Baron-Cohen et al., 2000; Amaral et al., 2003; Schumann \& Amaral, 2006), the fusiform gyrus (e.g. Schultz et al., 2003; van Kooten et al., 2008), the mirror neuron system (e.g. Oberman et al., 2005; Dapretto et al., 2006; Hadjikhani et al., 2006), and the superior temporal sulcus (e.g. Gervais et al., 2004; Hadjikhani et al., 2007). It can therefore be surmised that MBD within and/or between these key territories and pathways may be a nodal neurophysiological mechanism of ASD, responsible for various temporo-spatial processing disorders of visual and auditory stimuli. Further fMRI studies focusing on these various regions of interest could test this hypothesis in the future.

\section{$M B D$ and other neurobiological theories of ASD}

Our MBD hypothesis is in accordance with several other neurobiological theories of ASD, such as the temporal binding deficit hypothesis (Brock et al., 2002; see also Rippon et al., 2007), the theory of imbalance between neuronal excitation and inhibition (Rubenstein and Merzenich, 2003) and the neural information processing disorders hypothesis (Belmonte et al., 2004b; see also Belmonte \& Bourgeron, 2006). However, we moved a step further since our postulate i) is based on relevant data accounting for either under- or over-connectivity (and hypo- or hyper-synchronization) within/between local and distant networks, according to the nature of the tasks to be processed, ii) lies on functional disconnectivity involving not only cortical but also subcortical regions, and iii) accounts, via TSPD of multi-sensory stimuli, for a large spectrum of behavioral, cognitive and motor anomalies observed in ASD people .

\section{MBD in other developmental and neuro-psychiatric disorders}

Brain disconnectivity and dissynchrony is not specific to ASD and has been found to occur in other neurodevelopmental disorders such as epilepsy (e.g. Schevon et al., 2007), dyslexia (Cao et al., 2008), attention deficit/hyperactivity (Wolf et al., 2008), schizophrenia (Spencer, 2004; Symond et al., 2005; Uhlhaas et al., 2006), but also depression (Vasic et al., 2008) and neurodegenerative disorders, i.e. Parkinson's disease and Alzheimer's disease (Uhlhaas \& Singer, 2006 for a review). Brain dissynchrony and disconnectivity is therefore likely to constitute a universal signature of mental diseases. Further studies assessing and comparing brain connectivity and/or synchronization within and between various neurodevelopmental and mental disorders will uncover similarities and differences between their underlying neural and neuro-functional mechanisms.

\section{III- Neurobiological correlates}

In this section, we review some of the structural brain abnormalities that lie beneath MBD (Figure 2).

Anatomic neuroimaging studies during the last 20 years have shown that multiple cortical and subcortical areas are altered in adults with ASD, primarily the cerebellum (e.g. Courchesne et al., 1988, 1994), frontal (e.g. Carper and Courchesne, 2000) and temporal (e.g. Zilbovicius et al., 2000) cortices, hippocampus (Nicolson et al., 2006), amygdala (Aylward et al., 1999), and corpus callosum (Piven et al., 1997), and sometimes the brainstem, basal ganglia, striatum and thalamus (e.g. Cody et al., 2002; Santangelo \& Tsatsanis, 2005 for 
reviews). As highlighted by Müller (2007), ASD are distributed disorders, especially at the neuroanatomical and neurofunctional levels.

Post mortem studies, reviewed by Bauman \& Kemper (2005), revealed consistent findings in the limbic system, cerebellum and related inferior olive. Within the cerebellum, a significantly reduced number of Purkinje cells was reported. However, discrepancies were observed: in cerebellar nuclei and inferior olive, numerous and abnormally enlarged neurons were observed in the brains of young autistic subjects whereas small, pale and undernumbered neurons were described in adult autistic brains, strengthening the idea that the neuropathology of autism may represent an on-going process.

Likewise, Amaral et al. (2008)'s review on post mortem and structural magnetic resonance imaging studies highlighted the frontal lobes, amygdala and cerebellum as the most frequent pathological areas in autism. However, the authors conclude that there is no clear and consistent neuro-pathological signature that has emerged for autism, due to heterogeneity of both the core and co-morbid features of ASD. Moreover, the time course of brain development, rather than the final product, is most disturbed in autism.

Courchesne et al. $(2005,2007)$ underline that recent magnetic resonance imaging studies have revealed brain growth abnormalities involving gray and white matter in the first few years of life, sometimes followed by an arrest or a retardation of growth (e.g. Courchesne et al., 2001). Head circumference studies indicated that this early brain overgrowth might begin as early as the first year of life, thus, preceding and overlapping with the onset of the symptoms.

Finally, using a computerized imaging program to measure details of cell column morphologic features in the prefrontal and temporal cortices, Casanova et al. (2002) found that cell mini-columns in brains of autistic patients were more numerous, smaller, and less compact in their cellular configuration, with reduced neuropil space in the periphery. The authors inferred that increased number of mini-columns might result in a more extensive innervation and heightened activation, whereas the reduced neuropil spaces could induce a diminished lateral inhibition, possibly leading to an imbalance between neuronal excitation and neuronal inhibition, as postulated by Rubenstein \& Merzenich (2003). This minicolumnopathy may therefore account for association and high-order cognitive processes abnormalities seen in ASD (Casanova, 2007), as well as for the high incidence of epilepsy and epileptiform activity that are associated with ASD (Tuchman \& Rapin, 2002).

These various aspects of CNS formation found as disrupted in ASD may be at least partly correlated to genetic abnormalities inducing i) decreased apoptosis and/or increased cell proliferation, ii) altered cell migration with disrupted cortical and subcortical cytoarchitectonics and iii) abnormal cell differentiation with reduced neuronal size, and altered synaptogenesis. Alternatively, they may partly be due to environmental factors: in particular, brain enlargement can be related to neuroglial (i.e. astroglial and microglial) activation and neuroinflammation in the brain of patients with ASD (Vargas et al., 2005).

\section{IV-Genetic and environmental factors}

Many molecular abnormalities observed in ASD patients impact on the communication between neurons and therefore support MBD hypothesis of ASD (see e.g. Garber, 2007, and Figure 3).

\section{Genetic factors}

Data from numerous epidemiological, twin and family studies provided substantial evidence that ASD are amongst the most heritable complex brain disorders (e.g. Smalley et al., 1988; 
Folstein \& Rosen-Sheidley, 2001; Bacchelli and Maestrini, 2006). During the last decade, over 100 positional and/or functional candidate genes for autism were analyzed. Wholegenome screens in multiplex families indicate that 29 genes (Sutcliffe, 2008), and probably more, interact to predispose to ASD. Cytogenetic abnormalities in individuals with autism have been found in virtually every chromosome and new deleterious gene expressions are on the way to be identified (Abrahams and Geschwind, 2008). Determining specific genetic changes that increase the susceptibility to developing ASD is however extraordinarily complex due to the polygenic nature of these disorders and the interactions between genes and environmental influences through epigenetic processes. According to Happé et al. (2006), twin data and cognitive studies even suggest that non-overlapping genes act on each of the autistic traits, such as social impairment, communication difficulties and rigid and repetitive behaviors. However, it is currently accepted that ASD candidate genes encode products known to play a role in brain development and/or neurotransmission (Muhle et al., 2004). Copy number variations and mutations affecting genes implicated in cortical organization, synapse formation, synaptic transmission and neuromodulation have been found to be associated with ASD.

\section{Genes implicated in cortical organization}

Alterations in the protein Reelin (involved in neuronal migration and cortical layering during development) can affect cortical and cerebellar development. Mutations in the RELN gene and impaired Reelin signaling in ASD (Fatemi et al., 2005) are consistent with the cell migration defects found in autism and cerebellar neuronal abnormalities which are among the more consistent findings in ASD (Bauman \& Kemper, 2005).

The neurotrophin family, including nerve growth factor (NGF), brain-derived neurotrophic factor (BDNF), neurotrophin-3 and neurotrophin-4, is known to play a role in the regulation of cell proliferation and neuronal migration as well as in the modulation of axonal and dendritic growth and synapse formation. Elevated levels of BDNF have been found in the blood of children with ASD in several studies (e.g., Nelson et al., 2001) and auto-antibodies against BDNF were also found in serum of children with ASD or other associated syndromes (Connoly et al., 2006).

The tumor suppressor genes TSC1 and TSC2 are involved in cell growth regulation, dendrite morphology and glutamatergic neurotransmission (Tavazoie et al., 2005). Mutations have been identified in TSC1 and TSC2, which are responsible for tuberous sclerosis, a disorder often associated to mental retardation, epilepsy and autism (Baker et al., 1998). Abnormalities in genes involved in neuronal migration and corticogenesis, by their consequences on the construction of neural networks, may impact on neuronal communication (see e.g. Welsh et al., 2005).

\section{Genes implicated in synapse formation and synaptic plasticity}

Neuroligins are cell adhesion molecules, localized post-synaptically at glutamatergic (NLGN1, NLGN3 and NLGN4X/Y) or GABAergic synapses (NLGN2) (Varoqueaux et al., 2006). Mutations in the coding sequences of X-linked NLGN3 and NLGN4 have been identified in individuals with ASD and mental retardation (Jamain et al., 2003). Although these mutations have not been confirmed in other studies and probably explain less than $1 \%$ of ASD (Persico \& Bourgeron, 2006), they shed light on the potentially crucial role of synapse abnormalities in ASD. Another study showed that mutations in neuroligin 1 abolished neuroligin binding to neurexin 1 beta, and blocked synapse formation (Chubykin et al., 2005). Indeed, neuroligins, expressed post-synaptically, induce the formation of fully functional presynaptic terminals in contacting axons. Moreover, the association of NLGNs with scaffolding proteins is likely to regulate the glutamate-GABA equilibrium, which is 
impaired in the neuronal networks of 30-50\% ASD patients with clinical or infra-clinical epilepsy (Hughes \& Melyn, 2005; Tuchman \& Rapin, 2002). Another gene, SHANK3 (located in the 22q13 region), a neuroligin-binding partner regulating the structural organization of dendritic spines, has been found to be deleted in two brothers with ASD and delayed expressive speech (Durand et al., 2007).

Genes encoding neurexins (and particularly NRXN1) which are localized pre-synaptically and play an important role in glutamatergic and GABAergic synaptogenesis, via a neuroligin-neurexin link (Graf et al., 2004). These genes have clearly been implicated in ASD by the Autism Genome Project Consortium (2007) in the largest linkage scan of 1168 families with at least two individuals affected by ASD.

The Fragile-X syndrome, which is often accompanied by an autistic syndrome, is caused by mutations in the FMR1 gene (Chelly \& Mandel, 2001). The FMR1 gene, localized on chromosome X, encodes FMRP (fragile-X mental retardation protein), which is involved in mRNA transport and translation at the synapse (Bagni \& Greenough, 2005).

\section{Genes implicated in neurotransmission and neuromodulation}

Several studies reveal that variants of genes encoding neurotransmitter receptors and transporters might be susceptibility factors or modulators of the behavioral phenotype of ASD. The most studied gene involved in neurotransmission is SLC6A4, which encodes the serotonin transporter (5-HTT). Whereas Cook et al. (1997) found preferential inheritance of a short promoter variant of SLC6A4 in affected individuals, other teams reported that a long promoter variant of the 5-HTT transporter was inherited more frequently by affected family members (Yirmiya et al., 2001).

Several studies strongly suggest the involvement of glutamate receptors in the physiopathogeny of ASD (Muhle et al., 2004 for a review). For example, excessive glutamatergic activity is associated with epileptiform activity, which is frequently linked to autism (Tuchman \& Rapin, 2002; Hughes \& Melyn, 2005) and increased levels of glutamate have been found in adults with autism (Shinohe et al., 2006). An autistic population possessed a single amino acid substitution in GluR6 with a higher frequency than a control population (Jamain et al., 2002). Finally, the metabotropic glutamate receptor GRM8 in the chromosome 7q31-q33 autism susceptibility locus exhibits Linkage Disequilibrium with autism (Serajee et al., 2003).

In parallel, defects in the GABAergic inhibitory system have been found in ASD. Given its role in inhibiting excitatory neural pathways and its expression in early development (see below), it is not surprising that the $\mathrm{GABA}_{\mathrm{A}}$ receptor gene cluster (which contains genes for 3 of the receptor's subunits: GABRB3, GABRA5 and GABRG3 in chromosome 15q11-13) could be implicated in ASD (Menold et al., 2001). In addition to the GABA receptor genes themselves, genes involved in the differentiation and migration of GABAergic neurons have also been linked to ASD. Mutations in ARX (which encodes a transcription factor thought to regulate the development of GABAergic neurons in the basal ganglia and cortex) have been discovered in patients with epilepsy, movement disorders, cortical malformations, mental retardation and autism (Turner et al., 2002; see also Sherr, 2003, for a review). However, no association between ARX mutation and autism has been found in a study involving 226 patients with ASD and mental retardation (Chaste et al., 2007).

Deficiencies in i) GABA receptor expression or function and ii) differentiation and migration of GABAergic neurons into the cortex are likely involved in ASD. These findings are consistent with the idea that ASD can be caused by a reduced activity of GABAergic pathways, leading to hyperexcitability in neural networks and disorders in filtering out excessive stimuli from environmental and intrinsic sources (Rubenstein \& Merzenich, 2003). 
Finally, mutations of the 7-dehydrocholesterol reductase gene (DHCR7) cause the SmithLemli-Opitz syndrome (SLOS), an autosomal recessive malformation syndrome caused by a deficiency of the last step of cholesterol biosynthesis (Tint et al., 1994). Principal abnormalities of SLOS include facial dysmorphy and microcephaly, hypotonia, hypogenitalism, 2-3 toe syndactyly and a characteristic behavioral profile including autism, usually accompanied by mental retardation. Altered cholesterol metabolism may impact numerous stages of CNS development and functions including myelination, transport of serotonin, GABA and glutamate, steroid production and functioning of oxytocin receptor (Bukelis et al., 2007).

\section{Genes implicated in voltage-gated ion channels}

Recent studies reviewed by Krey \& Dolmetsch (2007) showed that functional mutations in genes encoding voltage-gated $\mathrm{Ca}^{2+}$ channels can lead to ASD. One of these studies reports the Timothy syndrome, a new multisystem disorder, often associated to autism, which is due to a recurrent de novo CACNAIC calcium channel mutation (Splawski et al., 2004). This mutation prevents voltage-dependent channel inactivation and leads to prolonged inward $\mathrm{Ca}^{2+}$ currents. Yet, these prolonged inward $\mathrm{Ca}^{2+}$ currents are known for their neurotoxicity, e.g. they are responsible for atrophy of dendritic spines and decreased synaptic connections, leading to apoptosis in socially isolated rats (Silva-Gomez et al., 2003).

Furthermore, mutations have been found in genes encoding other ion channels. These include several point mutations in $S C N 1 A$ and $S C N 2 A$, which encode the voltage-activated $\mathrm{Na}^{+}$ channels $\mathrm{Na}_{\mathrm{v}} 1.1$ and $\mathrm{Na}_{\mathrm{v}} 1.2$ respectively, both associated with childhood epilepsy and autism (Weiss et al., 2003). One of the mutations in SCN1A lies in the calmodulin binding site of the channel and reduces its affinity for $\mathrm{Ca}^{2+} /$ calmodulin.

Another study reports a decrease in $\mathrm{Ca}^{2+}$-activated $\mathrm{K}^{+}$channel $\left(\mathrm{BK}_{\mathrm{Ca}}\right)$ activity due to a disruption of the $\mathrm{BK}_{\mathrm{Ca}}$ gene (KCNMAl) in one subject with ASD (Laumonnier et al., 2006). The reported decrease in $\mathrm{BK}_{\mathrm{Ca}}$ channel activity, together with the reduced inactivation of voltage-gated $\mathrm{Ca}^{2+}$ channels in autistic patients, suggests that some forms of ASD are related to abnormally sustained increases of intracellular $\mathrm{Ca}^{2+}$ levels (Krey \& Dolmetsch, 2007).

\section{Environmental and epigenetic factors}

Genetic factors are undoubtedly important in the pathogenesis of ASD, as reviewed above and as indicated by much higher concordance rates among monozygotic twins when compared to dizygotic ones (Folstein \& Rosen-Sheidley, 2001). However, it cannot be ignored that prevalence of autism has spectacularly soared from 4 in 10,000 children in the 1960s to the current rate of 30-60 in 10,000 (Rutter, 2005). Although this increased prevalence in the last 40 years may be partly explained by changes in autism diagnostic criteria and growing awareness of the disorder (e.g. Waterhouse, 2008), there is also strong evidence to suggest that several environmental factors contribute, either per se or via epigenetic mechanisms, to the pathogenesis of ASD.

Pre- and perinatal infections by viral agents like rubella (Chess et al., 1978) and cytomegalovirus (Yamashita et al., 2003) have been found to increase the risk for ASD. These environmental factors are suspected to disrupt the normal encephalogenesis by perturbing neurodevelopmental pathways and/or interacting with the neuroimmune system. In addition, prenatal exposures to thalidomide (Strömland et al., 1994; Strömland et al., 2002) or valproic acid (Christianson, 1994; Rasalam et al., 2005) have also been found to be linked to ASD.

It has also been suggested that thimerosal, an ethylmercury derivative added in vaccines, could be partly responsible for the rising rates of ASD (Bernard et al., 2002; Desoto \& Hitlan, 2007). Although highly controversial (see e.g. the absence of correlation between autism and 
exposure to thimerosal in Heron \& Golding, 2004; see also Parker et al., 2004 for a review), this proposal raises the question of the detrimental role of threatening chemicals, found in increasing number in water and food, on brain development.

Recently, advanced maternal age has been identified as a risk factor for ASD, probably because of an increased risk for obstetric complications, such as low birth weight and shorter duration of gestation, and intrapartum hypoxia (Kolevzon et al., 2007, for a review). It is also recognized that advanced paternal age is associated to ASD (Reichenberg et al., 2006), a finding that might be related to de novo copy number variation in this population (Sebat et al., 2007).

To date, a limited number of studies have investigated the role of epigenetic misregulation in ASD. We can however cite a few: i) Rett syndrome, a pervasive developmental disorder characterized by autism, loss of language, hand wringing and seizures is due to mutation of MeCP2 (Amir et al., 1999); ii) children exposed in utero to sodium valproate (a medicine used for decades in the treatment of epilepsy and migraine) present an increased risk for ASD. It is now well established that valproic acid acts as a potent inhibitor of histone deacetylase activities (Göttlicher, 2004); iii) Prader-Willi and Angelman syndromes which are often associated to ASD may be due to abnormal methylation of the imprinted region of the UBE3A gene on chromosome 15q (Jiang et al., 2004); iv) finally, Hogart et al. (2007) showed that, in addition to alterations in absolute levels of gene expression, the relative expression of parental $\mathrm{GABA}_{\mathrm{A}}$ alleles is altered in $\mathrm{ASD}$, demonstrating a potential role for imprinting.

Research on epigenetic modifications in ASD is in its infancy and represents a promising avenue for a deeper insight on the nature and consequences of gene-environment interactions in ASD and other related disorders.

To summarize, environmental factors, per se or via epigenetic mechanisms, possibly in association with genetic abnormalities, are suspected to disrupt the normal encephalogenesis. They perturb neurodevelopmental pathways and/or interact with the neuroimmune system. As a consequence, brain development is impaired, resulting in structural and functional anomalies.

Overall, the genetic, environmental and epigenetic factors reviewed above, either alone or by complex interactions, are thought to induce a large amount of abnormalities in CNS development and functioning such as those seen in ASD and other related neurodevelopmental disorders, and referred to as MBD. It should however been precised that studies linking directly the former with the latter are quasi-absent, due to the lack of longitudinal and multidisciplinary studies including and integrating clinical and multi-level experimental considerations.

\section{V- Synthesis and conclusion}

The TSPD hypothesis aims at understanding and unifying numerous clinical and neuropsychological findings in ASD individuals. As shown, TSPDs of multi-sensory stimuli are defined as abnormalities in perceiving and integrating rapid and transient sensory events such as rapid physical movements, rapid facial movements, rapid speech flow and rapid proprioceptive inputs. TSPDs would consequently account for multiple cascades of disabilities in i) sensory-motor coupling, motor anticipation, inhibitory control and executive function, ii) higher order cognitive processes such as language abilities, iii) temporo-spatially grouping and associating multi-sensory and emotional stimuli in context and into coherent and meaningful patterns. TSPDs would also impact on the speed of perceptual, motor and cognitive processing, resulting in slowed and delayed motor and cognitive acts. Failing to process rapid sensory events online could consequently explain the difficulties and peculiarities of individuals with ASD in perceiving, imitating, understanding and producing emotional and verbal events on time, and therefore in interacting here and now with human 
and social environment. TSPDs may also be responsible for over-focused attention on static and local information, and thus for weak central coherence, and for deficits in empathizing, at the advantage of systemizing. Logically, slowing down visual and auditory events in the environment of children and adolescents with ASD (especially the most affected ones and those having the lowest developmental levels) has been demonstrated to enhance their performance in recognition and imitation of facial expressions and body gestures, and in verbal comprehension.

We hope that our TSPD and MBD approaches to the behavioral, motor and cognitive abnormalities seen in ASD people (see Figure 4 for a synthesis) may open new avenues for the comprehension of neurobio-, neurophysio- and neuropsycho-pathology of ASD as well as for the treatment of autistic people.

\section{Acknowledgements}

This work was financially supported by Fondation de France, Fondation Orange, CNRS and INSERM. We are grateful to the two reviewers who helped us to improve the manuscript. We are also grateful to Carole Tardif and Nouchine Hadjikhani for their helpful comments on the manuscript, and to Simon Baron-Cohen for his encouragements. We also warmly thank Sacha Gepner for his artistic contribution on the figures.

\section{References}

Abrahams, B.S., Geschwind, D.H., 2008. Advances in autism genetics: on the threshold of a new neurobiology. Nat Rev Genet, 9, 341-355.

Adrien, J.L., Lenoir, P., Martineau, J., Perrot, A., Hameury, L., Larmande C., Sauvage D., 1993. Blind ratings of early symptoms of autism based upon family home movies. J Am Acad Child Adolesc Psychiatry, 32, 617-626.

Allen G, Courchesne E., 2003. Differential effects of developmental cerebellar abnormality on cognitive and motor functions in the cerebellum: an fMRI study of autism. Am $\mathbf{J}$ Psychiatry, 160, 262-273.

Amaral DG, Bauman MD, Schumann C.M., 2003. The amygdala and autism: implications from non-human primate studies. Genes Brain Behav, 2, 295-302.

Amaral, D.G., Schumann, C.M., Nordahl, C.W., 2008. Neuroanatomy of autism. Trends Neurosci, 31, 137-145.

American Psychiatric Association, 2000. Diagnostic and Statistical Manual of Mental Disorders (DSM-IV-TR), APA: Washington DC.

Amir RE, Van den Veyver IB, Wan M, Tran CQ, Francke U, Zoghbi HY., 1999. Rett syndrome is caused by mutations in X-linked MECP2, encoding methyl-CpG-binding protein 2. Nat Genet, 23, 185-188.

Autism Genome Project Consortium, 2007. Mapping autism risk loci using genetic linkage and chromosomal rearrangements. Nat Genet, 39, 319-328.

Aylward, E.H., Minshew, N., Goldstein, G., Honeycutt, N.A., Augustine, A.M., Yates, K.O., Barta, P.E., Pearlson, G.D., 1999. MRI volumes of amygdala and hippocampus in nonmentally retarded autistic adolescents and adults. Neurology, 53, 175-183.

Babiloni, C., Bares, M., Vecchio, F., Brazdil, M., Jurak, P., Moretti, D.V., Ubaldi, A., Rossini, P.M., \& Rektor, I., 2004. Synchronization of gamma oscillations increases functional connectivity of human hippocampus and inferior-middle temporal cortex during repetitive visuomotor events. Eur J Neurosci, 19, 3088-3098. 
Bacchelli, E., Maestrini, E., 2006. Autism spectrum disorders: molecular genetic advances. Am J Med Genet, 142C: 13-23.

Bagni, C., Greenough, W.T., 2005. From mRNA trafficking to spine dysmorphogenesis. Nat Rev Neurosci, 6, 376-387.

Bailey, A., Luthert, P., Dean, A., Harding, B., Janota, I., Montgomery, M., Rutter, M., Lantos P., 1998. A clinicopathological study of autism. Brain, 121, 889-905.

Baker, P., Piven, J, Sato, Y., 1998. Autism and tuberous sclerosis complex: prevalence and clinical features. J Autism Dev Disord, 28, 279-285.

Baron-Cohen, S., 1995. Mindblindness. An essay on autism and Theory of mind. Cambridge: MIT Press.

Baron-Cohen S, Ring HA, Bullmore ET, Wheelwright S, Ashwin C, Williams SC., 2000. The amygdala theory of autism. Neurosci Biobehav Rev, 24, 355-364.

Baron-Cohen, S., 2002. The extreme male brain theory of autism. Trends Cogn Sci, 6, 248254.

Baron-Cohen, S., Knickmeyer, R.C., Belmonte, M.K., 2005. Sex differences in the brain: implications for explaining autism. Science, 310, 819-823.

Bauman, M.L., Kemper, T.L., 2005. Neuroanatomic observations of the brain in autism: a review and future directions. Int J Dev Neurosci, 23, 183-187.

Belmonte, M.K., Allen, G., Beckel-Mitchener, A., Boulanger, L.M., Carper, R.A., Webb, S.J., 2004a. Autism and abnormal development of brain connectivity. J Neurosci, 24, 9228-9231.

Belmonte MK, Cook EH Jr, Anderson GM, Rubenstein JL, Greenough WT, BeckelMitchener A, Courchesne E, Boulanger LM, Powell SB, Levitt PR, Perry EK, Jiang YH, DeLorey TM, Tierney E., 2004b. Autism as a disorder of neural information processing: directions for research and targets for therapy. Mol Psychiatry, 9, 646-663.

Belmonte, M.K., Bourgeron, T., 2006. Fragile X syndrome and autism at the intersection of genetic and neural networks. Nat Neurosci, 9, 1221-25.

Bernard S, Enayati A, Roger H, Binstock T, Redwood L., 2002. The role of mercury in the pathogenesis of autism. Mol Psychiatry. 7, S42-S43.

Bertone A., Mottron L., Jelenic P, Faubert J., 2003. Motion perception in autism: a 'complex' issue. J Cogn Neurosci, 15, 218-225.

Bonnel A, Mottron L, Peretz I, Trudel M, Gallun E, Bonnel A.M., 2003. Enhanced pitch sensitivity in individuals with autism: a signal detection analysis. J Cogn Neurosci, 15, 226-235.

Borgers, C., Kopell, N., 2003. Synchronization in networks of excitatory and inhibitory neurons with sparse, random connectivity. Neural Computers, 15, 509-538.

Breakspear, M., 2004. "Dynamic" connectivity in neural systems: theoretical and empirical considerations. Neuroinformatics, 2, 205-226.

Brock, J., Brown, C.C., Boucher, J., Rippon, G., 2002. The temporal binding deficit hypothesis of autism. Dev Psychopathol, 14, 209-224.

Brown, C., Gruber, T., Boucher, J., Rippon, G., Brock, J., 2005. Gamma abnormalities during perception of illusory figures in autism. Cortex, 41, 364-376.

Büchel, C., Friston, K., 2000. Assessing interactions among neuronal systems using functional neuroimaging. Neural Netw, 13, 871-882.

Bukelis I, Porter FD, Zimmerman AW, Tierney E., 2007. Smith-Lemli-Opitz syndrome and autism spectrum disorder. Am J Psychiatry, 164, 1655-1661.

Burack J.A., Enns, J.T., Stauder, J, Mottron, L., Randolph, B., 1997. Attention and autism: behavioral and electrophysiological evidence, in D. Cohen \& F. Volkmar (Eds), Handbook of Autism and Pervasive Developmental Disorders. New York: John Wiley and Sons. 
Cao F, Bitan T, Booth JR., 2008. Effective brain connectivity in children with reading difficulties during phonological processing. Brain Lang, 107, 91-101.

Carper, R.A., Courchesne, E., 2000. Inverse correlation between frontal lobe and cerebellum sizes in children with autism. Brain, 123, 836-844.

Casanova, M.F., Buxhoeveden, D.P., Switala, A.E. \& Roy, E., 2002. Minicolumnar pathology in autism. Neurology, 58, 428-432.

Casanova, M.F., 2007. The neuropathology of autism. Brain Pathol, 17, 422-433.

Castelli F., Frith C., Happé F., Frith U., 2002. Autism, Asperger syndrome and brain mechanisms for the attribution of mental states to animated shapes. Brain, 125, 18391849.

Chaste P, Nygren G, Anckarsäter H, Råstam M, Coleman M, Leboyer M, Gillberg C, Betancur C., 2007. Mutation screening of the ARX gene in patients with autism. Am J Med Genet B Neuropsychiatr Genet, 144B, 228-230.

Chelly, J., Mandel, J.L., 2001. Monogenic causes of X-linked mental retardation. Nat Rev Genet, 2, 669-680.

Cherkassky, V.L., Kana, R.K., Keller, T.A., Just, M.A., 2006. Functional connectivity in a baseline resting-state in autism. Neuroreport, 17, 1687-1690.

Chess, S., Fernandez, P., Korn, S., 1978. Behavioral consequences of congenital rubella. J Pediatrics, 93, 699-703.

Christianson AL, Chesler N, Kromberg JG., 1994. Fetal valproate syndrome: clinical and neuro-developmental features in two sibling pairs. Dev Med Child Neurol, 36, 361-369.

Chubykin AA, Liu X, Comoletti D, Tsigelny I, Taylor P, Südhof TC., 2005. Dissection of synapse induction by neuroligins: effect of a neuroligin mutation associated with autism. $\mathbf{J}$ Biol Chem, 280, 22365-22374.

Coben, R., Clarke, A.R., Hudspeth, W., Barry, R.J., 2008. EEG power and coherence in autistic spectrum disorder. Clin Neurophysiol, 119, 1002-1009.

Cody, H., Pelphrey, K., Piven, J., 2002. Structural and functional magnetic resonance imaging of autism. Int J Dev Neurosci, 20, 421-438.

Connolly, A.M., Chez, M., Streif, E.M., Keeling, R.M., Golumbek, P.T., Kwon, J.M., Riviello, J.J., Robinson, R.G., Neuman, R.J., Deuel, R.M.., 2006. Brain-derived neurotrophic factor and autoantibodies to neural antigens in sera of children with autistic spectrum disorders, Landau-Kleffner syndrome, and epilepsy. Biol Psychiatry, 59, 354363.

Cook, E.H., Courchesne, R., Lord, C., Cox, N.J., Yan, S., Lincoln, A., Haas, R., Courchesne, E., Leventhal, B.L., 1997. Evidence of linkage between the serotonin transporter and autistic disorder. Mol Psychiatry, 2, 247-250.

Courchesne, E., Yeung-Courchesne, R., Press, G., Hesselink, J.R., Jernigan, T.L., 1988. Hypoplasia of cerebellar vermal lobules VI and VII in autism. N Engl J Med, 318, 13491354.

Courchesne, E., Saitoh, O., Yeung-Courchesne, R., Press, G.A., Lincoln, A.J., Haas, R.H., Schreibman, L., 1994. Abnormality of cerebellar vermian lobules VI and VII in patients with infantile autism: identification of hypoplastic and hyperplastic subgroups with MR imaging. Am J Roentgenol, 162, 123-130.

Courchesne, E., Karns, C.M., Davis, H.R., Ziccardi, R., Carper, R.A., Tigue, Z.D., Chisum, H.J., Moses, P., Pierce, K., Lord, C., Lincoln, A.J., Pizzo, S., Schreibman, L., Haas, R.H., Akshoomoff, N.A., Courchesne, R.Y., 2001. Unusual brain growth patterns in early life in patients with autistic disorder : an MRI study. Neurology, 57, 245-254.

Courchesne E, Redcay E, Morgan JT, Kennedy DP, 2005. Autism at the beginning: microstructural and growth abnormalities underlying the cognitive and behavioral phenotype of autism. Dev Psychopathol, 17, 577-597. 
Courchesne, E., Pierce, K., Schumann, C.M., Redcay, E., Buckwalter, J.A., Kennedy, D.P., Morgan, J., 2007. Mapping early brain development in autism. Neuron, 56, 399-413.

Critchley HD, Daly EM, Bullmore ET, Williams SC, Van Amelsvoort T, Robertson DM, Rowe A, Phillips M, McAlonan G, Howlin P, Murphy DG., 2000. The functional neuroanatomy of social behaviour: changes in cerebral blood flow when people with autistic disorder process facial expressions. Brain, 123, 2203-2212.

Dakin S, Frith U., 2005. Vagaries of visual perception in autism. Neuron, 48, 497-507.

Dalton KM, Nacewicz BM, Johnstone T, Schaefer HS, Gernsbacher MA, Goldsmith HH, Alexander AL, Davidson RJ., 2005. Gaze fixation and the neural circuitry of face processing in autism. Nat Neurosci, 8, 519-526.

Damasio A.R., Maurer, R.G., 1978. A neurological model for childhood autism. Arch Neurol, 35, 777-786.

Dapretto, M., Davies, M.S., Pfeifer, J.H., Scott, A.S., Sigman, M., Bookheimer, S.Y., Iacobini, M., 2006. Understanding emotions in others: mirror neuron dysfunction in children with autism spectrum disorders. Nat Neurosci, 9, 28-30.

Davies, S., Bishop, D., Manstead, A.S.R., Tantam, D., 1994. Face perception in children with autism and Asperger's syndrome. J Child Psychol Psychiatry, 35, 1033-1057.

Dawson G, Webb SJ, McPartland J., 2005. Understanding the nature of face processing impairment in autism: insights from behavioral and electrophysiological studies. Dev Neuropsychol, 27, 403-424.

De Gelder, B., Vroomen, J., Van der Heide, L., 1991. Face recognition and lip-reading in autism. Eur J Cogn Psychol, 3, 69-86.

DeMeyer, M.K., Alpern, G.D., Barton, S., De Meyer, W.E., Churchill, D.W., Hingtgen, J.N., Bryson, C.Q., Pontius, W., Kimberlin, C., 1972. Imitation in autistics, early schizophrenic, and nonpsychotic subnormal children. J Autism Child Schizophr, 2, 264-287.

Deruelle, C., Rondan, C., Gepner, B., Tardif, C., 2004. Spatial frequency and face processing in children with autism and Asperger syndrome. J Autism Dev Disord, 34, 199-210.

Desoto, M.C., Hitlan, R.T., 2007. Blood levels of mercury are related to diagnosis of autism: a reanalysis of an important data set. J Child Neurol, 22, 1308-1311.

Doya, K., 2000. Complementary roles of basal ganglia and cerebellum on learning and motor control. Curr Opin Neurobiol, 10, 732-739.

Durand, C.M., Betancur, C., Boeckers, T.M., Bockmann, J., Chaste, P., Fauchereau, F., Nygren, G., Rastam, M., Gillberg, C., Anckarsäter, H., Sponheim, E., Goubran-Botros, H., Delorme, R., Chabane, N., Mouren-Simeoni, M.C., de Mas, P., Bieth, E., Rogé, B., Héron, D., Burglen, L., Gillberg, C., Leboyer, M., Bourgeron, T., 2007. Mutations in the gene encoding the synaptic scaffolding protein SHANK3 are associated with autism spectrum disorders. Nat Genet, 39, 25-27.

Fatemi, S.H., Snow, A.V., Stary, J.M., Araghi-Niknam M, Reutiman TJ, Lee S, Brooks AI, Pearce DA, 2005. Reelin signaling is impaired in autism. Biol Psychiatry, 57, 777-787.

Fingelkurts AA, Fingelkurts AA, Kähkönen S., 2005. Functional connectivity in the brain--is it an elusive concept? Neurosci Biobehav Rev, 28, 827-836.

Folstein, S.E., Rosen-Sheidley, B., 2001. Genetics of autism: complex aetiology for a heterogeneous disorder. Nat Rev Genet, 2, 943-955.

Fombonne, E., 2002. Epidemiological trends in rates of autism. Mol Psychiatry, 7, S4-S6. Frith U., 1989. Autism : explaining the enigma. $2^{\text {nd }}$ Edition, Oxford, Basic Blackwell, 2003. Frith, U., 2001. Mindblindness and the brain in autism. Neuron, 32, 969-979.

Gaab N, Gabrieli JD, Deutsch GK, Tallal P, Temple E., 2007. Neural correlates of rapid auditory processing are disrupted in children with developmental dyslexia and ameliorated with training: an fMRI study. Restor Neurol Neurosci, 25, 295-310. 
Garber, K., 2007. Autism's cause may reside in abnormalities at the synapse. Science, 317, 190-191.

Gepner, B., Soulayrol, R., 1994. Usefulness of the concepts of epigenesis and selforganization for the comprehension of autistic syndromes. Psychiatrie Enf, XXXVII, 1, 115-152.

Gepner, B., Mestre, D., Masson, G., de Schonen, S., 1995. Postural effects of motion vision in young autistic children. NeuroReport, 6, 1211-1214.

Gepner, B., de Gelder, B. \& de Schonen, S., 1996. Face processing in autistics: Evidence for a generalized deficit? Child Neuropsychol, 2, 123-139.

Gepner, B., 1997. Facial recognition and visual-motion perception in autism. Unpublished doctoral dissertation. University of Aix-Marseille.

Gepner B., 2001. «Malvoyance» du mouvement dans l'autisme infantile ? Une nouvelle approche neuropsychopathologique développementale. Psychiatrie Enf, XLIV, 1, 77-126.

Gepner B., Deruelle C., Grynfeltt S., 2001. Motion and emotion: a novel approach to the study of face processing by autistic children. J Autism Dev Disord, 31, 37-45.

Gepner B., Massion, J. (dir by), 2002. L'autisme : une pathologie du codage temporel ? Trav Interdisciplin Lab Parole Lang, 21, 177-218.

Gepner B., Mestre D., 2002a. Postural reactivity to fast visual motion differentiates autistic from children with Asperger syndrome. J Autism Dev Disord, 32, 231-238.

Gepner B., Mestre D., 2002b. Rapid visual-motion integration deficit in autism. Trends Cogn Sci, 6, 455.

Gepner, B., 2004. Autism, movement and facial processing. Am J Psychiatry, 161, 1719.

Gepner, B., Lainé, F., Tardif, C., 2005. E-Motion mis-sight and other temporal processing disorders in autism. Cahiers de Psychologie Cognitive/Current Psychology of Cognition, 23, 104-121.

Gepner B., Tardif C., 2006. Autism, movement, time and thought. E-motion mis-sight and other temporo-spatial processing disorders in autism, in: M. Vanchevsky (ed). Frontiers in Cognitive Psychology. New York : Nova Science Publishers, pp. 1-30.

Gepner, B., 2008. From neuronal to human communication disorders: a novel approach to autism. Interactions, 1, 1-26. htpp://www.revue-interactions.fr

Gervais, H., Belin, P., Boddaert, N, Leboyer M, Coez A, Sfaello I, Barthélémy, C, Brunelle F, Samson Y, Zilbovicius, M., 2004. Abnormal cortical voice processing in autism. Nat Neurosci, 7, 801-802.

Geschwind, D.H., Levitt, P., 2007. Autism spectrum disorders: developmental disconnection syndromes. Curr Opin Neurobiol, 17, 103-111.

Glickstein, M., Stein, J., 1991. Paradoxical movement in Parkinson's disease. Trends Neurosci, 14, 480-482.

Göttlicher M., 2004. Valproic acid: an old drug newly discovered as inhibitor of histone deacetylases. Ann Hematol, 83, S91-S92

Graf, E.R., Zhang, X., Jin, S.X., Linhoff, M.W. \& Craig, A.M., 2004. Neurexins induce differentiation of GABA and glutamate postsynaptic specializations via neuroligins. Cell, 119, 1013-1026.

Grandin T., 1995. Thinking in pictures and other reports from my life with autism, Doubleday.

Green D, Charman T, Pickles A, Chandler S, Loucas T, Simonoff E, Baird G., 2009. Impairment in movement skills of children with autistic spectrum disorders. Dev Med Child Neurol. 51, 311-316.

Hadjikhani N, Joseph RM, Snyder J, Tager-Flusberg H., 2006. Anatomical differences in the mirror neuron system and social cognition network in autism. Cereb Cortex, 16, 12761282. 
Hadjikhani N, Joseph RM, Snyder J, Tager-Flusberg H., 2007. Abnormal activation of the social brain during face perception in autism. Hum Brain Mapp, 28, 441-449.

Happé, F., Ronald, A., Plomin, R., 2006. Time to give up on a single explanation for autism. Nat Neurosci, 9, 1218-1220.

Happé F., 1999. Autism: Cognitive deficit or cognitive style? Trends Cogn Sci, 3, 216-222.

Happé, F, Frith, U., 2006. The weak coherence account: detail-focused cognitive style in autism spectrum disorders. J Autism Dev Disord, 36, 5-25.

Heron, J., Golding, J., 2004. Thimerosal exposure in infants and developmental disorders: a prospective cohort study in the United Kingdom does not support a causal association. Pediatrics, 114, 577-583

Hill, E.L., 2004. Executive dysfunction in autism. Trends Cogn Sci, 8, 26-32.

Hobson, R.P., Ouston, J., Lee, A., 1988. What's in a face? The case of autism. Br J Psychol, 79, 441-453.

Hogart A, Nagarajan RP, Patzel KA, Yasui DH, Lasalle JM, 2007. 15q11-13 GABAA receptor genes are normally biallelically expressed in brain yet are subject to epigenetic dysregulation in autism-spectrum disorders. Hum Mol Genet, 16, 691-703.

Horwitz, B., Rumsey, J., Grady, C., Rapoport, S., 1988. The cerebral metabolic landscape in autism. Intercorrelations of regional glucose utilization. Arch Neurol, 45, 749-755.

Hughes, C., Russell, J., Robbins, T.W., 1994. Evidence for executive dysfunction in autism. Neuropsychologia, 32, 477-492.

Hughes, J.R., Melyn, M., 2005. EEG and seizures in autistic children and adolescents: further findings with therapeutic implications. Clin EEG Neurosci, 36, 15-20.

Hutt, C., Hutt, S.J., Lee, D., Ounsted, C., 1964. Arousal and childhood autism. Nature, 4961, 908-909.

Ito, M.,1984. The cerebellum and neural control. New York: Raven Press.

Jamain, S., Betancur, C., Quach, H., Philippe, A., Fellous, M., Giros, B., Gillberg, C., Leboyer, M., Bourgeron, T., Paris Autism Research International Sibpair (PARIS) Study, 2002. Linkage and association of the glutamate receptor gene with autism. Mol Psychiatry, 7, 302-310.

Jamain, S., Quach, H., Betancur, C., Råstam, M., Colineaux, C., Gillberg, I.C., Soderstrom, H., Giros, B., Leboyer, M., Gillberg, C., Bourgeron, T., Paris Autism Research International Sibpair Study, 2003. Mutations of the X-linked genes encoding neuroligins NLGN3 and NLGN4 are associated with autism. Nat Genet, 34, 27-29.

Jiang YH, Sahoo T, Michaelis RC, Bercovich D, Bressler J, Kashork CD, Liu Q, Shaffer LG, Schroer RJ, Stockton DW, Spielman RS, Stevenson RE, Beaudet AL , 2004. A mixed epigenetic/genetic model for oligogenic inheritance of autism with a limited role for UBE3A. Am J Med Genet A, 131, 1-10.

Johnson, M.T., Ebner, T.J., 2000. Processing of multiple kinematic signals in the cerebellum and motor cortices. Brain Res Review, 33, 155-168.

Just, M.A., Cherkassky, V.L., Keller, T.A., Minshew, N.J., 2004. Cortical activation and synchronization during sentence comprehension in high-functioning autism: evidence of underconnectivity. Brain, 127, 1811-1821.

Just, MA, Cherkassky VL, Keller TA, Kana RK, Minshew NJ., 2007. Functional and anatomical cortical underconnectivity in autism: evidence from an FMRI study of an executive function task and corpus callosum morphometry. Cereb Cortex 17, 951-961.

Kana RK, Keller TA, Cherkassky VL, Minshew NJ, Just MA., 2006. Sentence comprehension in autism: thinking in pictures with decreased functional connectivity. Brain, 129, 24842493. 
Kana RK, Keller TA, Minshew NJ, Just MA., 2007. Inhibitory control in high-functioning autism: decreased activation and underconnectivity in inhibition networks. Biol Psychiatry, 62, 198-206.

Kanner, L., 1943. Autistic disturbances of affective contact. Nervous Child, 2, 217-250.

Kemper TL, Bauman ML., 1993. The contribution of neuropathologic studies to the understanding of autism. Neurol Clin, 11, 175-187.

Kennedy DP, Courchesne E., 2008. The intrinsic functional organization of the brain is altered in autism. Neuroimage, 39, 1877-1885.

Kleinhans NM, Richards T, Sterling L, Stegbauer KC, Mahurin R, Johnson LC, Greenson J, Dawson G, Aylward E., 2008. Abnormal functional connectivity in autism spectrum disorders during face processing. Brain, 131, 1000-1012.

Klin, A., Jones, W., Schultz, R., Volkmar, F., Cohen, D., 2002. Visual fixation patterns during viewing of naturalistic social situations as predictors of social competence in individuals with autism. Arch Gen Psychiatry, 59, 809-816.

Kohen-Raz, R., Volkmar, F.R., Cohen, D.J., 1992. Postural control in children with autism. J Autism Dev Disord, 22, 419-432.

Kolevzon A, Gross R, Reichenberg A., 2007, Prenatal and perinatal risk factors for autism: a review and integration of findings. Arch Pediatr Adolesc Med,161, 326-333.

Krey, J.F., Dolmetsch, R.E., 2007. Molecular mechanisms of autism: a possible role for Ca2+ signaling. Curr Opin Neurobiol, 17, 112-119.

Lainé, F., Tardif, C., Rauzy, S., Gepner, B., 2008a. Perception et imitation du mouvement dans l'autisme: une question de temps. Enfance, 2, 140-157.

Lainé, F., Tardif, C., Gepner, B., 2008b. Slowing down biological motion and speech sounds enhances imitation and verbal comprehension in children and adolescents with autism. Poster at the Autism Neuroscience Conference, Royal Society, London, October.

Lainé, F., Rauzy, S., Gepner, B., Tardif, C. (in press). Prise en compte des difficultés de traitement des informations visuelles et auditives rapides dans le cadre de l'évaluation diagnostique de l'autisme. Enfance.

Laumonnier, F., Roger, S., Guérin, P., Molinari, F., M'rad, R., Cahard, D., Belhadj A, Halayem M, Persico AM, Elia M, Romano V, Holbert S, Andres C, Chaabouni H, Colleaux L, Constant, J., Le Guennec, J.Y., Briault, S., 2006. Association of a functional deficit of the BKCa channel, a synaptic regulator of neuronal excitability, with autism and mental retardation. Am J Psychiatry, 163, 1622-1629.

Leary, M.R., Hill, D.A., 1996. Moving on : autism and movement disturbances. Ment Retard, 34, 39-53.

Lecavalier, L., 2006. Behavioral and emotional problems in young people with pervasive developmental disorders: relative prevalence, effects of subject characteristics, and empirical classification. J Autism Dev Disord, 36, 1101-1114.

Loveland, K.A., Tunali-Kotoski, B., Pearson, D.A., Brelsford, K.A., Ortegon, J., Chen, R. 1994. Imitation and expression of facial affect in autism. Dev Psychopathol, 6, 433-444.

Massion J., 1993.Grandes relations anatomo-fonctionnelles dans le cervelet. Rev Neurol, 11, 600-606.

McPartland J, Dawson G, Webb SJ, Panagiotides H, Carver LJ., 2004. Event-related brain potentials reveal anomalies in temporal processing of faces in autism spectrum disorder. $\mathbf{J}$ Child Psychol Psychiatry, 45, 1235-1245

Menold, M.M., Shao, Y., Wolpert, C.M., Donnelly SL, Raiford KL, Martin ER, Ravan SA, Abramson RK, Wright HH, Delong GR, Cuccaro ML, Pericak-Vance MA, Gilbert, J.R., 2001. Association analysis of chromosome 15 GABAA receptor subunit genes in autistic disorder. J Neurogenet, 15, 245-259. 
Mestre, D., Rondan, C., Masson, G., Castet, E., Deruelle, C., Gepner, B., 2002. Evaluation de la vision du mouvement chez des enfants autistes au moyen du nystagmus opto-cinétique. Trav Interdisciplin Lab Parole Lang, 21,192-198.

Middleton, F.A., Strick, P.L., 2000. Basal ganglia and cerebellar loops: motor and cognitive circuits. Brain Res Brain Res Rev, 31, 236-250.

Milne, E., Swettenham, J., Hansen, P., Campbell, R., Jeffries, H., Plaisted, K., 2002. High motion coherence thresholds in children with autism. J Child Psychol Psychiatry, 43, 255-263.

Milne, E., Swettenham, J., \& Campbell, R., 2005. Motion perception and autistic spectrum disorder: a review. Cahiers de Psychologie Cognitive/Current Psychology of Cognition, 23, 3-36.

Minshew, N.J., Williams, D.L., 2007. The new neurobiology of autism: cortex, connectivity and neuronal organization. Arch Neurol, 64, 945-950.

Mizuno, A., Villalobos, M.E., Davies, M.M., Dahl, B.C., Muller, R.A., 2006. Partially enhanced thalamocortical functional connectivity in autism. Brain Res, 1104, 160-174.

Mottron L, Peretz I, Ménard E., 2000. Local and global processing of music in highfunctioning persons with autism: beyond central coherence? J Child Psychol Psychiatry, 41, 1057-1065.

Mottron, L., 2004. L'autisme: une autre intelligence. Sprimont: Mardaga.

Muhle, R., Trentacoste, S.V., Rapin, I., 2004. The genetics of Autism. Pediatrics, 113, e472e486.

Müller R.A., 2007. The study of autism as a distributed disorder. Ment Retard Dev Disabil Res Rev, 13, 85-95.

Murias M, Webb SJ, Greenson J, Dawson G., 2007. Resting state cortical connectivity reflected in EEG coherence in individuals with autism. Biol Psychiatry, 62, 270-273.

Nelson, K.B., Grether, J.K., Croen, L.A., Dambrosia JM, Dickens BF, Jelliffe LL, Hansen RL, Phillips, T.M., 2001. Neuropeptides and neurotrophins in neonatal blood of children with autism or mental retardation. Ann Neurol, 49, 597-606.

Nicolson R, DeVito TJ, Vidal CN, Sui Y, Hayashi KM, Drost DJ, Williamson PC, Rajakumar N, Toga AW, Thompson PM., 2006. Detection and mapping of hippocampal abnormalities in autism. Psychiatry Res, 148, 11-21.

Nishitani, N., Avikainen, S., Hari, R., 2004. Abnormal imitation-related cortical activation sequences in Asperger's syndrome. Ann Neurol, 55, 558-562.

Oberman, L.M., Hubbard, E.M., McCleery, J.P., Altschuler, E.L., Ramachandran, V.S., Pineda, J.A., 2005. EEG evidence for mirror neuron dysfunction in autism spectrum disorders. Brain Res Cogn Brain Res, 24, 190-198.

Oram Cardy JE, Flagg EJ, Roberts W, Brian J, Roberts TP., 2005. Magnetoencephalography identifies rapid temporal processing deficit in autism and language impairment. Neuroreport, 16, 329-332.

Orekhova, E.V., Stroganova, T.A., Nygren, G., Tsetlin, M.M., Posikera, I.N., Gillberg, C., Elam, M., 2007. Excess of high frequency electroencephalogram oscillations in boys with autism. Biol Psychiatry, 62, 1022-1029.

Ornitz, E.M., Ritvo, E.R., 1968. Perceptual inconstancy in early infantile autism. Arch Gen Psychiatry, 18, 76-98.

Ornitz, E.M., 1974. The modulation of sensory input and motor output in autistic children. J Autism Child Schizophrenia, 4, 197-215.

Ornitz, E.M., Brown, M.B., Mason, A., Putnam, N.H., 1974. Effect of visual input on vestibular nystagmus in autistic children. Arch Gen Psychiatry, 31, 369-375.

Osterling, J., Dawson, G., 1994. Early recognition of children with autism: a study of first birthday home videotapes. J Autism Dev Disord, 24, 247-257. 
Parker SK, Schwartz B, Todd J, Pickering LK., 2004. Thimerosal-containing vaccines and autistic spectrum disorder: a critical review of published original data. Pediatrics, 114, 793-804.

Pellicano, E., Gibson, L., Maybery, M., Durkin, K., Badcock, D.R., 2005. Abnormal global processing along the dorsal visual pathway in autism: a possible mechanism for weak visuospatial coherence? Neuropsychologia, 43, 1044-1053.

Pelphrey, K.A., Morris, J.P., McCarthy, G., LaBar K.S., 2007. Perception of dynamic changes in facial affect and identity in autism. Soc Cogn Affect Neurosci, 2, 140-149.

Persico, A.M., Bourgeron, T., 2006. Searching for ways out of the autism maze: genetic, epigenetic and environmental cues. Trends Neurosci, 29, 349-358.

Piven, J., Bailey, J., Ransom, B., Arndt, S., 1997. An MRI study of the corpus callosum in autism. Am J Psychiatry, 54, 1051-1056.

Rapin I., 2002. The autistic spectrum disorders. New England J Med, 347, 302-303.

Rapin, I., Dunn, M., 2003. Update on the language disorders of individuals on the autistic spectrum. Brain Dev, 25, 166-172.

Rasalam AD, Hailey H, Williams JH, Moore SJ, Turnpenny PD, Lloyd DJ, Dean J.C., 2005. Characteristics of fetal anticonvulsant syndrome associated autistic disorder. Dev Med Child Neurol, 47, 551-555.

Reichenberg A, Gross R, Weiser M, Bresnahan M, Silverman J, Harlap S, Rabinowitz J, Shulman C, Malaspina D, Lubin G, Knobler HY, Davidson M, Susser E., 2006, Advancing paternal age and autism. Arch Gen Psychiatry. 2006, 63, 1026-1032.

Rippon, G., Brock, J., Brown, C., Boucher, J., 2007. Disordered connectivity in the autistic brain: Challenges for the 'new psychophysiology'. Int J Psychophysiol, 63, 164-172.

Rogers, S.J., Pennington, B.F., 1991. A theoretical approach to the deficits in infantile autism. Dev Psychopathol, 3, 137-162.

Rogers, S.J., Hepburn, S.L., Stackhouse, T., Wehner, E., 2003. Imitation performance in toddlers with autism and those with other developmental disorders. J Child Psychol Psychiatry, 44, 763-781.

Rubenstein, J.L., Merzenich, M.M., 2003. Model of autism: increased ratio of excitation/inhibition in key neural systems. Genes Brain Behav, 2, 255-267.

Rutter, M., 2005. Incidence of autism spectrum disorders: changes over time and their meaning. Acta Paediatr, 94, 2-15.

Santangelo, S.L., Tsatsanis, K., 2005. What is known about autism: genes, brain and behavior. Am J Pharmacogenomics, 5, 71-92.

Sauvage D., 1988. Autisme du nourrisson et du jeune enfant. Paris: Masson.

Schevon CA, Cappell J, Emerson R, Isler J, Grieve P, Goodman R, McKhann G Jr, Weiner H, Doyle W, Kuzniecky R, Devinsky O, Gilliam F., 2007. Cortical abnormalities in epilepsy revealed by local EEG synchrony. Neuroimage, 35, 140-148.

Schmitz C., Assaiante C., Gepner B., 2002. Modulation de la réponse anticipée en fonction du poids à délester : étude chez l'enfant sain et l'enfant autiste. Trav Interdisciplin Lab Parole Lang, 21, 207-211.

Schmitz C., Martineau J., Barthélémy C., Assaiante C., 2003. Motor control and children with autism : deficit of anticipatory function? Neurosci Lett, 348, 17-20.

Schmitz N, Daly E, Murphy D., 2007. Frontal anatomy and reaction time in Autism. Neurosci Lett, 412, 12-17.

Schultz RT, Grelotti DJ, Klin A, Kleinman J, Van der Gaag C, Marois R, Skudlarski P., 2003. The role of the fusiform face area in social cognition: implications for the pathobiology of autism. Philos Trans R Soc Lond B Biol Sci, 358, 415-427.

Schumann CM, Amaral DG., 2006. Stereological analysis of amygdala neuron number in autism. J Neurosci, 26, 7674-7679. 
Sebat, J., Lakshmi, B., Malhotra, D., Troge, J., Lese-Martin, C., Walsh, T., Yamrom, B., Yoon, S., Krasnitz, A., Kendall, J. et al., 2007. Strong association of de novo copy number mutations in autism. Science, 316, 445-449.

Serajee, F.J., Zhong, H, Nabi, R., Huq, A.H., 2003. The metabotropic glutamate receptor 8 gene at 7q31: partial duplication and possible association with autism. J Med Genet, 40, e42.

Sherr, E.H., 2003. The ARX story (epilepsy, mental retardation, autism, and cerebral malformations): one gene leads to many phenotypes. Curr Opin Pediatr, 15, 567-571.

Shinohe, A., Hashimoto, K., Nakamura, K. Shinohe A, Hashimoto K, Nakamura K, Tsujii M, Iwata Y, Tsuchiya KJ, Sekine Y, Suda S, Suzuki K, Sugihara G, Matsuzaki H, Minabe Y, Sugiyama T, Kawai M, Iyo M, Takei N, Mori, N., 2006. Increased serum levels of glutamate in adult patients with autism. Prog Neuropsychopharmacol Biol Psychiatry, 30, $1472-1477$.

Silva-Gómez AB, Rojas D, Juárez I, Flores G., 2003. Decreased dendritic spine density on prefrontal cortical and hippocampal pyramidal neurons in post-weaning social isolation rats. Brain Res, 983, 128-136.

Singer, W., 1999. Neural synchrony: a versatile code for the definition of relations? Neuron, 24, 49-65.

Singer, W., 2007. What do disturbances in neural synchrony tell us about autism? Biol Psychiatry, 62, 190-191.

Smalley SL, Asarnow RF, Spence MA., 1988. Autism and genetics. A decade of research. Arch Gen psychiatry, 45, 953-961.

Speer LL, Cook AE, McMahon WM, Clark E., 2007. Face processing in children with autism: effects of stimulus content and type. Autism, 11, 265-277.

Spencer, J., O'Brien, J., Riggs, K., Braddick, O., Atkinson, J., Wattam-Bell, J., 2000. Motion processing in autism: evidence for a dorsal stream deficiency. NeuroReport, 11, 27652767.

Spencer, K.M., Nestor, P.G., Perlmutter, R., Niznikiewicz, M.A., Klump, M.C., Frumin, M., Shenton, M.E., McCarley, R.W., 2004. Neural synchrony indexes disordered perception and cognition in schizophrenia. Proc Natl Acad Sci (USA), 101, 17288-17293.

Splawski, I., Timothy, K.W., Sharpe, L.M., Decher N, Kumar P, Bloise R, Napolitano C, Schwartz PJ, Joseph RM, Condouris K, Tager-Flusberg H, Priori SG, Sanguinetti MC, Keating, M.T., 2004. Cav1.2 calcium channel dysfunction causes a multisystem disorder including arrhytmia and autism. Cell, 119, 19-31.

Strömland, K. Nordin, V., Miller, M., Akerström, B., Gillberg, C., 1994. Autism in thalidomide embryopathy: a population study. Dev Med Child Neurol, 36, 351-356.

Strömland K, Philipson E, Andersson Grönlund M., 2002. Offspring of male and female parents with thalidomide embryopathy: birth defects and functional anomalies. Teratology, 66, 115-121.

Sutcliffe, J.S., 2008. Insights into the pathogenesis of autism. Science, 321, 208-209.

Symond, M.P., Harris, A.W., Gordon, E., Williams, L.M., 2005. "Gamma synchrony" in firstepisode schizophrenia: a disorder of temporal connectivity? Am J Psychiatry, 162, 459465.

Tager-Flusberg, H., Caronna, E., 2007. Language disorders: autism and other pervasive developmental disorders. Pediatr Clin North Am, 54, 469-481.

Takarae, Y., Minshew, N.J., Luna, B., Krisky, C.M., Sweeney, J.A., 2004. Pursuit eye movement deficits in autism. Brain, 127, 2584-94.

Tallal, P., 1976. Rapid auditory processing in normal and disordered language development. J Speech Hear Res, 19, 561-594. 
Tallal, P., Miller, S.L., Bedi, G., Byma G, Wang X, Nagarajan SS, Schreiner C, Jenkins WM, Merzenich, M.M., 1996. Language comprehension in language-learning impaired children improved with acoustically modified speech. Science, 271, 81-83.

Tallal, P., Gaab, N., 2006. Dynamic auditory processing, musical experience and language development. INMED/TINS special issue: Nature and nurture in development and neurological disorders. Trends Neurosci, 29, 382-390.

Tammett, D., 2006. Born on a blue day, inside the extraordinary mind of an autistic savant. Hodder \& Stoughton.

Tardif, C., Lainé, F., Rodriguez, M., Gepner, B., 2007. Slowing down facial movements and vocal sounds enhances facial expression recognition and facial-vocal imitation in children with autism. J Autism Dev Disord, 37, 1469-1484.

Tardif, C., Thomas, K., Gepner, B., Rey, V., 2002. Contribution à l'évaluation du système phonologique explicite chez des enfants autistes. Parole, 21, 35-72.

Tardif, C., Gepner, B., 2003. L'autisme. Paris: Armand Colin, $2^{\text {nd }}$ Edition, 2007.

Tavazoie SF, Alvarez VA, Ridenour DA, Kwiatkowski DJ, Sabatini BL., 2005. Regulation of neuronal morphology and function by the tumor suppressors TSC1 and TSC2. Nat Neurosci, 8, 1727-1734.

Teitelbaum, P., Teitelbaum, O., Nye, J., Fryman, J., Maurer, R., 1998. Movement analysis in infancy may be useful for early diagnosis of autism. Proc Natl Acad Sci, 95, 1398213987.

Teitelbaum O, Benton T, Shah PK, Prince A, Kelly JL, Teitelbaum P., 2004. EshkolWachman movement notation in diagnosis: the early detection of Asperger's syndrome. Proc Natl Acad Sci U S A, 101, 11909-11914.

Timme, M., Wolf, F., Geisel, T., 2004. Topological speed limits to network synchronization. Phys Rev Lett, 92, 074101.

Tint, GS, Irons, M, Elias, ER, Batta, AK, Frieden, R, Chen, TS, Salen, G., 1994. Defective cholesterol biosynthesis associated with the Smith-Lemli-Opitz syndrome. N Engl J Med, 330, 107-113.

Townsend, J., Harris, N.S., Courchesne, E., 1996. Visual attention abnormalities in autism: delayed orienting to location. J Int Neuropsychol Soc, 2, 541-550.

Tuchman, R., Rapin, I., 2002. Epilepsy in autism. Lancet Neurol, 1, 352-358.

Turner, G., Partington, M., Kerr, B., Mangelsdorf, M., Gecz, J., 2002. Variable expression of mental retardation, autism, seizures and dystonic hand movements in two families with an identical ARX gene mutation. Am J Med Genet, 112, 405-411.

Turner, K.C., Frost, L., Linsenbardt, D., Mellroy, J.R., Muller, R.A., 2006. Atypically diffuse functional connectivity between caudate nuclei and cerebral cortex in autism. Behav Brain Funct, 16, 2-34.

Uhlhaas, P., Singer, W., 2006. Neural synchrony in brain disorders: relevance for cognitive dysfunctions and pathophysiology. Neuron, 52, 155-168.

Uhlhaas PJ, Linden DE, Singer W, Haenschel C, Lindner M, Maurer K, Rodriguez E., 2006. Dysfunctional long-range coordination of neural activity during Gestalt perception in schizophrenia. J Neurosci., 26, 8168-8175.

Van Dalen J.G.T, 1994. L'autisme vu de l'intérieur: Voir avec les yeux d'une personne légèrement autiste. Engagement NVA, 11-16.

Van Kooten IA, Palmen SJ, von Cappeln P, Steinbusch HW, Korr H, Heinsen H, Hof PR, van Engeland H, Schmitz C., 2008. Neurons in the fusiform gyrus are fewer and smaller in autism. Brain, 131, 987-999.

Varela, F., Lachaux, J.P., Rodriguez, E., Martinerie, J., 2001. The Brainweb : phase synchronization and large-scale integration. Nat Rev Neurosci, 2, 229-239. 
Vargas, D.L., Nascimbene, C., Krishnan, C., Zimmerman, A.W., Pardo, C.A., 2005. Neuroglial activation and neuroinflammation in the brain of patients with autism. Ann Neurol, 57, 67-81.

Varoqueaux, F., Aramuni, G., Rawson, R.L., Mohrmann, R., Missler, M., Gottmann, K., Zhang W, Südhof TC, Brose, N., 2006. Neuroligins determine synapse maturation and function. Neuron, 51, 741-754.

Vasic N, Walter H, Sambataro F, Wolf RC., 2008. Aberrant functional connectivity of dorsolateral prefrontal and cingulate networks in patients with major depression during working memory processing. Psychol Med, 10, 1-11.

Villalobos, M.E., Mizuno, A., Dahl, B.C., Kemmotsu, N., Muller, R.A., 2005. Reduced functional connectivity between $\mathrm{V} 1$ and inferior frontal cortex associated with visuomotor performance in autism. Neuroimage, 15, 916-925.

Vivanti G, Nadig A, Ozonoff S, Rogers SJ., 2008. What do children with autism attend to during imitation tasks? J Exp Child Psychol., 101, 186-205.

Volkmar, F. R., Pauls, D., 2003. Autism. Lancet, 362, 1133-1141.

Wainwright-Sharp, J.A., Bryson S.E., 1993. Visual orienting deficits in high-functioning people with autism. J Autism Dev Disord , 23, 1-13.

Waterhouse L., 2008. Autism overflows: increasing prevalence and proliferating theories. Neuropsychol Rev, 18, 273-286.

Weiss, L.A., Escayg, A., Kearney, J.A., Trudeau M, MacDonald BT, Mori M, Reichert J, Buxbaum JD, Meisler, M.H., 2003. Sodium channels SCN1A, SCN2A and SCN3A in familial autism. Mol Psychiatry, 186-194.

Welsh, J.P., Ahn, E.S., Placantonakis, D.G., 2005. Is autism due to brain desynchronization ? Int J Dev Neurosci, 23, 253-263.

Werner E, Dawson G., 2005. Validation of the phenomenon of autistic regression using home videotapes. Arch Gen Psychiatry, 62, 889-895.

Wickelgren, I., 2005. Autistic brains out of synch? Science, 308, 1856-1858.

Wicker, B., Fonlupt, P., Hubert, B., Tardif, C., Gepner, B., Deruelle, C., 2008. Abnormal cerebral effective connectivity during explicit emotional processing in adults with autism spectrum disorder. Soc Cogn Affect Neurosci, 3, 135-143.

Williams, D., 1992. Nobody Nowhere. London: Doubleday.

Williams, J.H., Whiten, A., Singh, T., 2004. A systematic review of action imitation in autistic spectrum disorder. J Autism Dev Disord, 34, 285-299.

Wilson TW, Rojas DC, Reite ML, Teale PD, Rogers SJ., 2007. Children and adolescents with autism exhibit reduced MEG steady-state gamma responses. Biol Psychiatry, 62, 192-197.

Wolf RC, Plichta MM, Sambataro F, Fallgatter AJ, Jacob C, Lesch KP, Herrmann MJ, Schönfeldt-Lecuona C, Connemann BJ, Grön G, Vasic N., 2008. Regional brain activation changes and abnormal functional connectivity of the ventrolateral prefrontal cortex during working memory processing in adults with attention-deficit/hyperactivity disorder. Hum Brain Mapp. 2008 Dec 23 [Epub].

Wong TK, Fung PC, Chua SE, McAlonan GM., 2008. Abnormal spatiotemporal processing of emotional facial expressions in childhood autism: dipole source analysis of eventrelated potentials. Eur J Neurosci, 28, 407-416.

World Health Organization, 1992. The ICD-10 Classification of Mental and Behavioural Disorders (ICD-10), Geneva: WHO.

Yamashita, Y., Fujimoto, C., Nakajima, E., Isagai, T., Matsuishi, T., 2003. Possible association between congenital cytomegalovirus infection and autistic disorder. J Autism Dev Disord, 33, 455-459. 
Yirmiya, N., Pilowsky, T., Nemanov, L., Arbelle S, Feinsilver T, Fried I, Ebstein RP, 2001. Evidence for an association with the serotonin transporter promoter region polymorphism and autism. Am J Med Genet, 105, 381-386.

Zilbovicius M., Boddaert N., Belin P., Poline J.B., Remy P., Mangin J.F., Thivard L., Barthélémy C., Samson Y. 2000. Temporal lobe dysfunction in childhood autism: a PET study. Am J Psychiatry, 157, 1988-1993.

Zwaigenbaum, L., Bryson, S., Rogers, T., Roberts, W., Brian, J., Szatmari, P., 2005. Behavioral manifestations of autism in the first year of life. Int J Dev Neurosci, 23, 143152. 
Figure 1. Behavioral, motor and cognitive consequences of Temporo-Spatial Processing Disorders (TSPD) of multi-sensory flows.

Findings by our group revealed the existence of TSPDs of multi-sensory flows in subjects with ASD, including various degrees of disability in perceiving and integrating visual, auditory and proprioceptive stimuli online and in producing real-time sensory-motor coupling, postural adjustments and adequate verbal and nonverbal outputs. TSPDs are considered as central early neuropsychological disorders, resulting in numerous maldevelopmental cascades, i.e. the various behavioral, motor and cognitive manifestations seen in ASD subjects. In the first or second year of life, ASD children display basic sensory and sensory-motor anomalies and, later in life, their disturbances become more complex and intricate, affecting higher order cognitive functions. Each maldevelopmental cascade is represented with a specific colour (red for visual-motion processing deficit, yellow for speech flow processing deficit, blue for proprioceptive flow processing deficit). Disorders generated by two distinct sensory cascades are represented in a composite colour (e.g. violet for disorders generated by visual and proprioceptive processing deficits). Disorders generated by three distinct sensory pathways are represented in white.

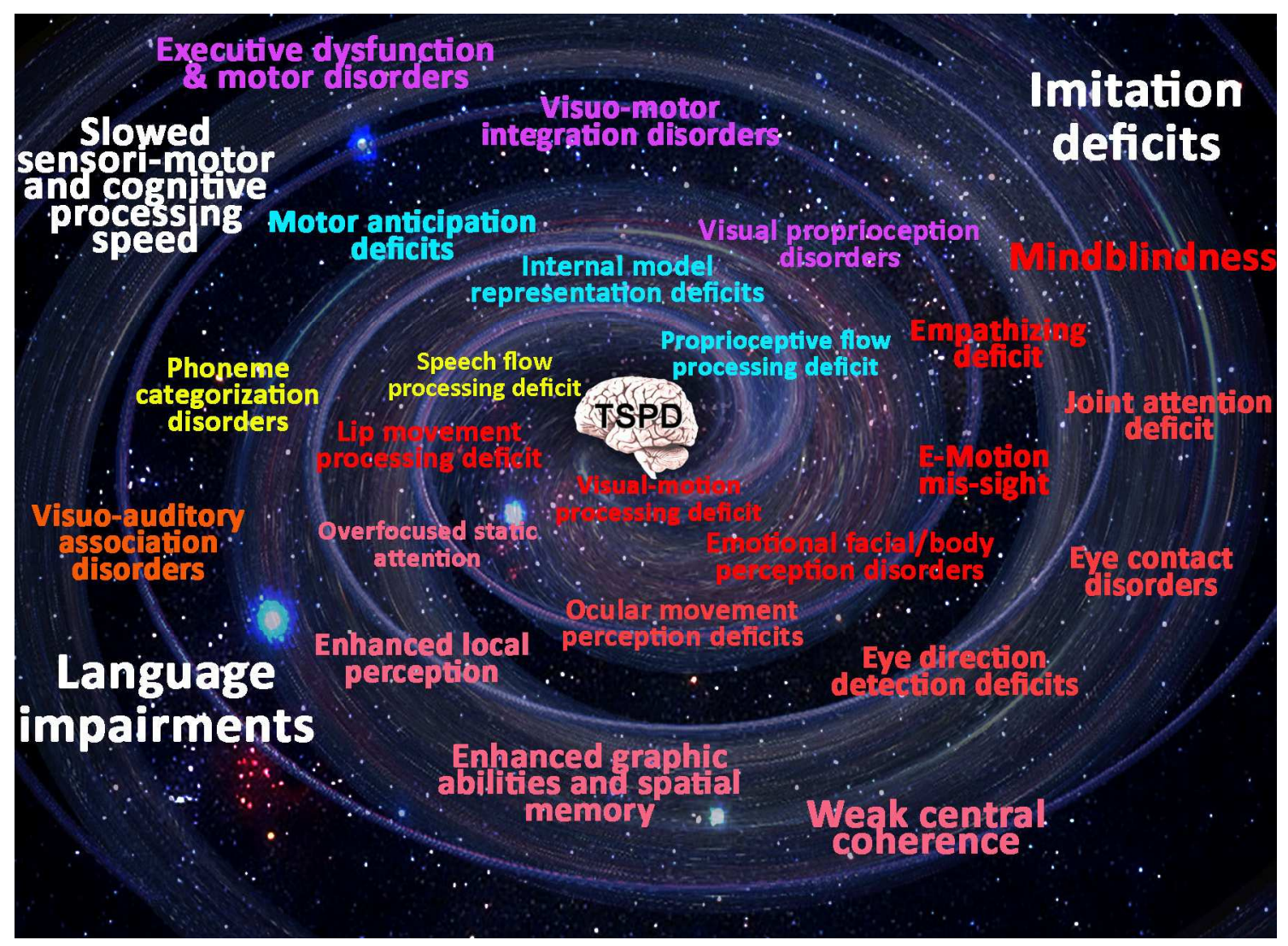


Figure 2. The main functional and structural brain abnormalities in ASD.

The Multisystem Brain Disconnectivity-Dissynchrony (MBD) hypothesis includes numerous functional brain anomalies (i.e. functional under- or over-connectivity, neuronal hypo- or hyper-synchrony, within/between multiple brain areas and pathways). Structural brain abnormalities underlie MBD.

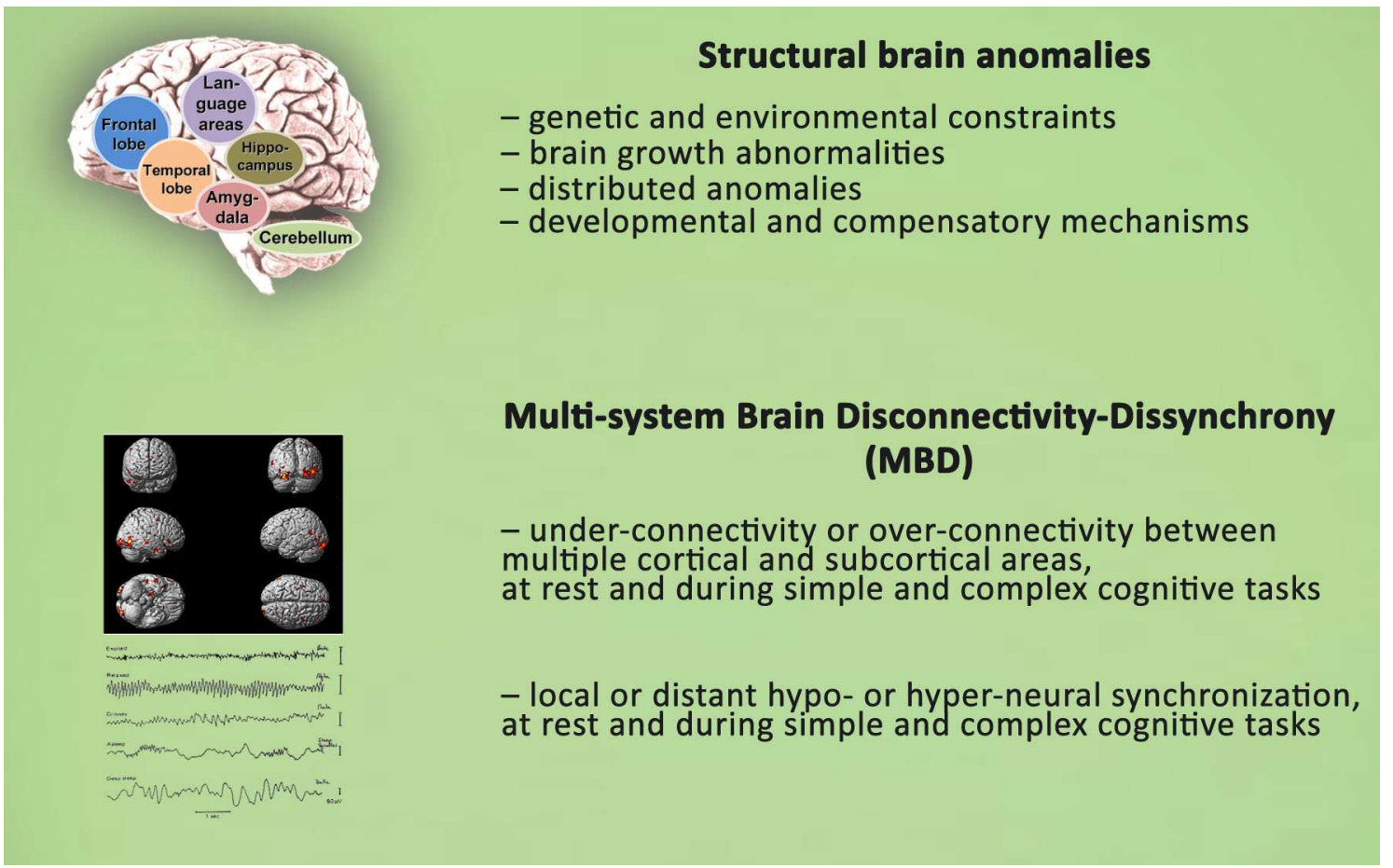


Figure 3. Selection of misexpressed genes in ASD brains.

A subset of genetic abnormalities (reelin, neurotrophin family...) impacts on neuronal migration and corticogenesis. Another subset of genetic anomalies affects synaptogenesis (neuroligins, neurexins, Shank3) and neurotransmission (serotonin transporter, GABA and glutamate receptors, voltage-gated ion channels). As a consequence, neural networks and inter-neuron communication are disrupted.

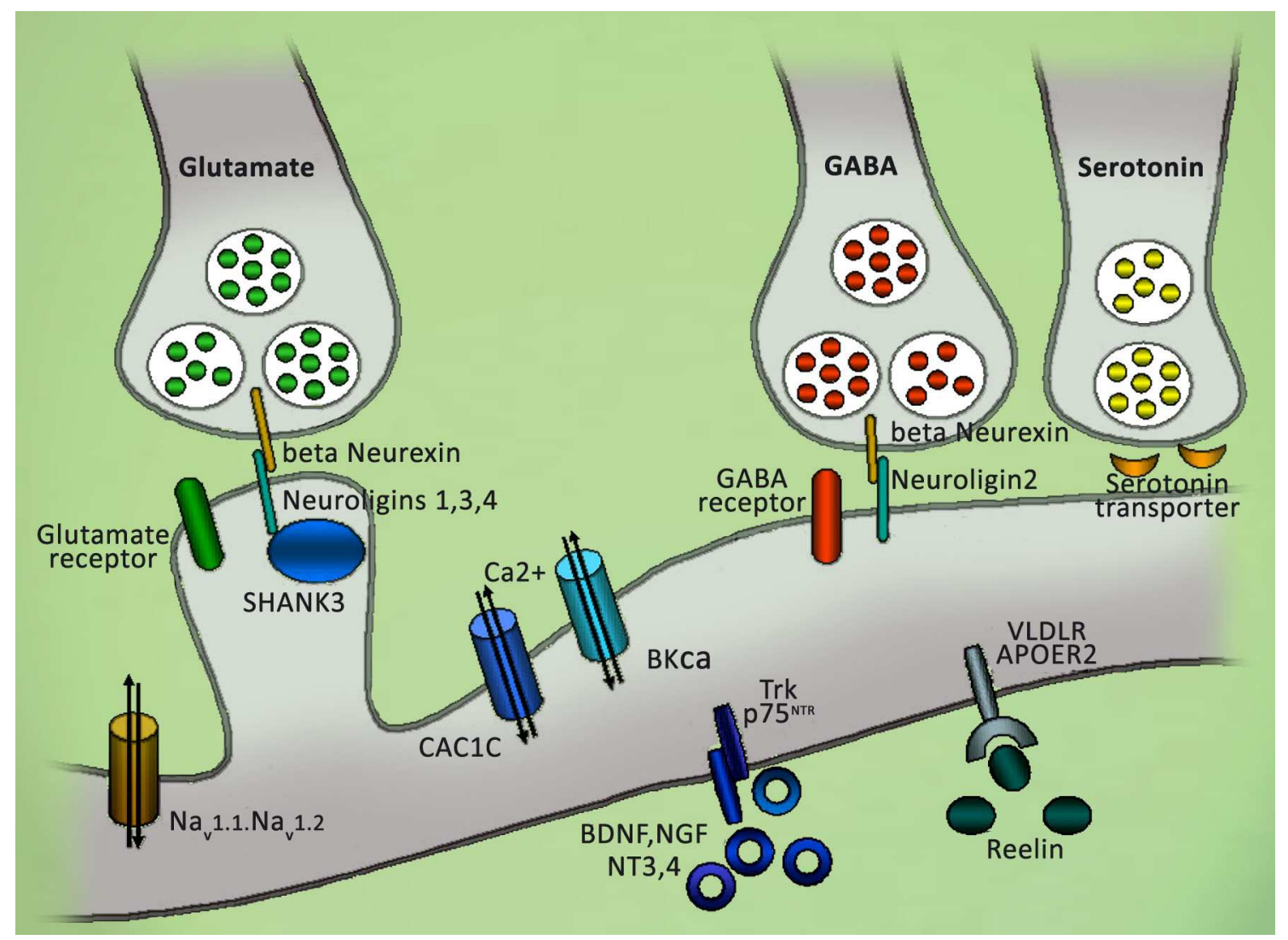


Figure 4. Schematic overview of our TSPD and MBD approaches to ASD.

Genetic, environmental and epigenetic anomalies induce structural brain abnormalities that are responsible for Multisystem Brain Disconnectivity-Dissynchrony (MBD). As a result, the autistic brain is affected by various temporo-spatial processing disorders (TSPD) of multisensory stimuli that in turn generate numerous behavioral, motor and cognitive dysfunctions.

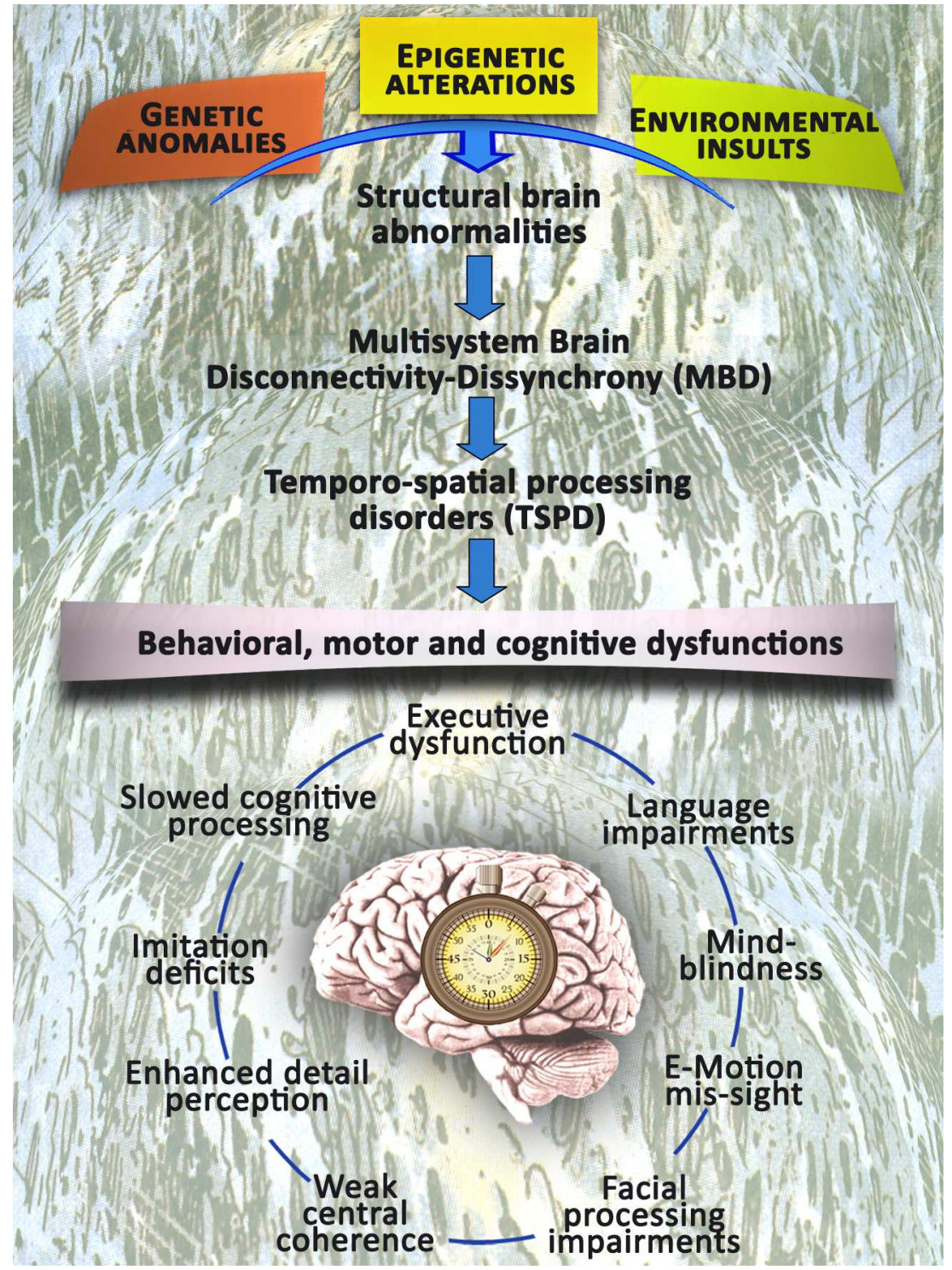

